\title{
Identification of Candidate COVID-19 Therapeutics using hPSC-derived Lung Organoids
}

Authors: Yuling Han ${ }^{1, \#}$, Liuliu Yang ${ }^{1, \#}$, Xiaohua Duan ${ }^{1,11 \#, ~ F u y u ~ D u a n ², ~}{ }^{2}$, Benjamin E. NilssonPayant $^{3, \#}$, Tomer M. Yaron ${ }^{4,}$,, Pengfei Wang ${ }^{6}$, Xuming Tang ${ }^{1}$, Tuo Zhang ${ }^{7}$, Zeping Zhao ${ }^{1}$, Yaron Bram $^{8,9}$, David Redmond ${ }^{10}$, Sean Houghton ${ }^{10}$, Duc Nguyen ${ }^{8,9}$, Dong Xu ${ }^{7}$, Xing Wang ${ }^{7}$, Skyler $\mathrm{Uhl}^{3}$, Yaoxing Huang ${ }^{6}$, Jared L. Johnson ${ }^{4}$, Jenny Xiang ${ }^{7}$, Hui Wang ${ }^{11,12}$, Fong Cheng Pan ${ }^{1}$, Lewis C. Cantley ${ }^{4, *}$, Benjamin R. tenOever ${ }^{3, *}$, David D. Ho ${ }^{6, *}$, Todd Evans ${ }^{1, *}$, Robert E. Schwartz ${ }^{8,9, *}$ Huanhuan Joyce Chen ${ }^{2, *}$, Shuibing Chen ${ }^{1, *}$

\section{Affiliations}

${ }^{1}$ Department of Surgery, Weill Cornell Medicine, 1300 York Ave, New York, NY, 10065, USA.

2 The Pritzker School of Molecular Engineering, the Ben May Department for Cancer Research, the University of Chicago, IL. USA.

${ }^{3}$ Department of Microbiology, Icahn School of Medicine at Mount Sinai. 1468 Madison Ave. New York, NY, 10029, USA.

${ }^{4}$ Meyer Cancer Center, Weill Cornell Medicine, New York, NY 10021

${ }^{5}$ Englander Institute for Precision Medicine, Institute for Computational Biomedicine, Weill Cornell Medicine, New York, NY 10065, USA

${ }^{6}$ Aaron Diamond AIDS Research Center, Columbia University Irving Medical Center, New York, NY 10032, USA

${ }^{7}$ Genomic Resource Core Facility, Weill Cornell Medicine, New York, NY 10065, USA. 
${ }^{8}$ Division of Gastroenterology and Hepatology, Department of Medicine, Weill Cornell Medicine, 1300 York Ave, New York, NY, 10065, USA.

${ }^{9}$ Department of Physiology, Biophysics and Systems Biology, Weill Cornell Medicine, 1300 York Ave, New York, NY, 10065, USA.

${ }^{10}$ Division of Regenerative Medicine, Ansary Stem Cell Institute, Weill Cornell Medicine, New York, NY, 10065, USA

${ }^{11}$ State Key Laboratory of Oncogenes and Related Genes, Center for Single-Cell Omics, School of Public Health, Shanghai Jiao Tong University School of Medicine, Shanghai 200025, China.

${ }^{12}$ School of Life Science and Technology, ShanghaiTech University, 201210 Shanghai, China.

\# These authors contributed equally: Yuling Han, Liuliu Yang, Xiaohua Duan, Fuyu Duan, Benjamin Nilsson-Payant, Tomer M. Yaron

\section{*Corresponding authors}

Correspondence to Dr. Shuibing Chen (lead contact): shc2034@,med.cornell.edu

Dr. Huanhuan Joyce Chen: joycechen@uchicago.edu

Dr. Robert E. Schwartz: res2025@med.cornell.edu

Dr. Todd Evans: tre2003@med.cornell.edu

Dr. David D. Ho: dh2994@,cumc.columbia.edu

Dr. Benjamin tenOever: benjamin.tenoever@mssm.edu

Dr. Lewis C. Cantley: LCantley@med.cornell.edu 


\section{Summary Paragraph}

The SARS-CoV-2 virus has caused already over 3.5 million COVID-19 cases and 250,000 deaths globally. There is an urgent need to create novel models to study SARS-CoV-2 using human disease-relevant cells to understand key features of virus biology and facilitate drug screening. As primary SARS-CoV-2 infection is respiratory-based, we developed a lung organoid model using human pluripotent stem cells (hPSCs) that could be adapted for drug screens. The lung organoids, particularly aveolar type II cells, express ACE2 and are permissive to SARS-CoV-2 infection. Transcriptomic analysis following SARS-CoV-2 infection revealed a robust induction of chemokines and cytokines with little type I/III interferon signaling, similar to that observed amongst human COVID-19 pulmonary infections. We performed a high throughput screen using hPSC-derived lung organoids and identified FDA-approved drug candidates, including imatinib and mycophenolic acid, as inhibitors of SARS-CoV-2 entry. Pre- or post-treatment with these drugs at physiologically relevant levels decreased SARS-CoV-2 infection of hPSC-derived lung organoids. Together, these data demonstrate that hPSC-derived lung cells infected by SARS-CoV2 can model human COVID-19 disease and provide a valuable resource to screen for FDAapproved drugs that might be repurposed and should be considered for COVID-19 clinical trials. 
The ongoing COVID-19 pandemic is an unprecedented global event that requires the immediate deployment of effective clinical therapeutics while vaccine candidates are identified and tested. Arguably the most rapid means of addressing this issue is through the repurposing of existing drugs that are FDA-approved which may indirectly interfere with aspects of SARS-CoV-2 biology. While this strategy is being pursued, most high throughput screens focus on the use of transformed cell lines which fail to capture the physiologically relevant dynamics of a SARS-CoV-2 infection. In an effort to improve on these cell lines, we developed and describe here lung organoids as an improved in vitro platform for screening purposes.

In the last several years, a series of protocols have been reported to direct hPSC differentiation to various lung lineages ${ }^{1-14}$. We differentiated hPSCs to lung organoids using a previously reported stepwise strategy ${ }^{4,15}$, including the progressive differentiation first into definitive endoderm (DE), followed by specification to anterior foregut endoderm (AFE), AFE/lung progenitor cells (LPs), and finally lung organoids (Extended Data Fig. 1). Single cell transcriptomic profiles were generated and analyzed in the differentiated lung organoids at day 50 and identified alveolar type II (AT2) cells (SP-B $\left.{ }^{+}, \mathrm{SP}_{-} \mathrm{D}^{+}, \mathrm{ABCA3}^{+}\right)$, alveolar type I (AT1) cells $\left(\mathrm{PDPN}^{+} \mathrm{APQ}^{+}\right)$, stromal cells, and proliferating cells (Fig. 1a, 1b and Extended Data Fig. 2b). We also detected a low number of pulmonary neuroendocrine cells $\left(\mathrm{ASCL}^{+}, \mathrm{CALCA}^{+}\right)$and airway epithelial cells (Fig. 1a and Extended Data Fig. 2a, 2b). ACE2, the putative receptor for SARS-CoV-2 ${ }^{16}$, is mainly detected in cluster 1, which represents AT2 cells (Fig. 1c, 1d). TMPRSS2, a key transmembrane protease for SARS-CoV-2 infection ${ }^{16}$, is also enriched in AT2 cells and AT1 cells (Fig. 1c, 1d). Consistent with scRNA-seq data of adult lung ${ }^{17}$, ACE2 and TMPRSS2 expression are detected in only a subset of the AT2 cells, likely due to the depth limitation of 10X scRNA-seq. Immunostaining results further validated that ACE2 is expressed in $\mathrm{SP}-\mathrm{B}^{+} / \mathrm{SP}-\mathrm{C}^{+} \mathrm{AT} 2$ cells (Fig. 1e). 
To determine the relative permissiveness of hPSC-derived lung organoids to SARS-CoV-2 viral entry, we first used a vesicular stomatitis virus (VSV) based SARS-CoV-2 pseudo-entry virus, for which the backbone was provided by a VSV-G pseudo-typed $\Delta \mathrm{G}$-luciferase virus with the SARSCoV-2 Spike protein incorporated at the surface of the viral particle (See Methods for details) ${ }^{18,19}$. Robust luciferase activity was readily detected in the infected hPSC-derived lung organoids (Fig. 1f).

To generate an in vivo model using human lung organoids, we implanted subcutaneously day 25 lung progenitor cells in immuno-deficient NSG mice (Fig. 1g). Within 4 months the xenografts developed organized alveolar-like structures (Fig. 1h). Immunostaining confirms the existence of $\mathrm{SP}^{+} \mathrm{B}^{+}$AT2 cells, which co-express ACE2 (Fig. 1i). Infection of SARS-CoV-2 pseudo-entry virus was tested in this mouse model carrying hPSC-derived lung xenografts. Expression of luciferase from the SARS-CoV-2 pseudo-entry virus was detected by immunofluorescence staining 24 hours after intra-xenograft inoculation $\left(1 \mathrm{X} 10^{4} \mathrm{FFU}\right)$. LUC is mainly detected in SP-B ${ }^{+}$AT2 cells (Fig. 1j).

The potential of the hPSC-derived lung organoid platform to model COVID-19 was then tested by infection with SARS-CoV-2 virus in the cultures. 24 hours post inoculation (hpi) with the SARSCoV-2 virus (USA-WA1/2020, MOI=0.01), qRT-PCR using primers targeting $\mathrm{N}$ sgRNA transcripts confirmed that a significant amount of replicating viral RNA was detected in the infected lung organoids (Fig. 2a). Immunostaining confirmed the detection of SARS-S protein in 
the infected lung organoids (Fig. 2b). At 24 hpi, RNA-seq was performed on mock and SARSCoV-2 infected cells. Alignment with the viral genome confirmed robust viral replication in hPSCderived lung organoids (Fig. 2c). Moreover, plotting these datasets by principle component analysis (PCA) suggested that the infected lung organoids clustered distinctly compared to mockinfected lung organoids (Fig. 2d). Volcano plots of SARS-CoV-2 infected hPSC-derived lung organoids compared to mock treatment revealed robust induction of chemokines and cytokines with no detectable levels of type I and III IFNs (Fig. 2e). Gene set enrichment analysis (GSEA) comparing mock-infected versus SARS-CoV-2 infected lung organoids revealed over-represented pathway networks including TNF signaling, IL-17 signaling, chemokine signaling pathway, and cytokine-cytokine receptor interaction (Fig. 2f). These profiles were further compared with primary tissues from healthy and COVID-19 patients. Compared with healthy lung, lung tissues of COVID-19 patients revealed robust induction of chemokines, including CXCl2, CCL2, CXCL3 as well as $I L 1 A, B C R C 3, A A D A C$, and $A T P B 4$ (Fig. 2g), which is markedly similar to SARS-CoV2 infected lung organoids. Finally, IL-17 signaling was also found to be significantly changed in lung tissues of COVID-19 patients, which is consistent with SARS-CoV-2 infected lung organoids (Fig. 2h).

To identify drug candidates capable of blocking SARS-CoV-2 pseudo-virus infection, hPSCderived lung organoids were deposited onto 384-well plates. After six hour of incubation, organoids were treated at $10 \mu \mathrm{M}$ with a library of FDA-approved drugs (the Prestwick collection). Two hour post-treatment, the organoids were innoculated with SARS-CoV-2 pseudo-entry virus at $\mathrm{MOI}=0.01$. At $24 \mathrm{hpi}$, the organoids were analyzed for luciferase activity. The wells in which $\mathrm{Z}$ score $<-2$ were chosen as primary hit drugs (Fig. 3a). The hits were evaluated for efficacy and 
cytotoxicity at different concentrations. Four drugs were confirmed to block luciferase activity in a dose-dependent manner, independent of cytotoxicity, including imatinib $\left(\mathrm{EC}_{50}=4.86 \mu \mathrm{M}\right.$, $\mathrm{IC}_{50}=37.3 \mu \mathrm{M}$ Fig. 3b, 3e), mycophenolic acid (MPA, $\mathrm{EC}_{50}=0.15 \mu \mathrm{M}$, Fig. 3c, 3f), quinacrine dihydrochloride (QNHC, $\mathrm{EC}_{50}=2.83 \mu \mathrm{M}, \mathrm{IC}_{50}=22 \mu \mathrm{M}$, Fig. 3d, 3g), chloroquine ( $\left.\mathrm{EC}_{50}=3.85 \mu \mathrm{M}\right)$, and prochlorperazine $\left(\mathrm{EC}_{50}=23.7 \mu \mathrm{M}, \mathrm{IC}_{50}=30 \mu \mathrm{M}\right)($ Extended Data Fig. 3). Interestingly, three hit compounds, MPA, QNHC, and chloroquine, were also identified from our independent screen using hPSC-derived colonic organoids ${ }^{20}$. Immunostaining confirmed a significant diminishment of $\mathrm{LUC}^{+}$cells detected among SP-C AT2 cells in lung organoids treated with $10 \mu \mathrm{M}$ imatinib, 3 $\mu \mathrm{M}$ MPA or $4.5 \mu \mathrm{M}$ QNHC at 24 hpi (Fig. 3h).

To evaluate the drug activities in vivo, we used humanized mice carrying hPSC-derived lung xenografts after 4 months maturation in vivo (Fig. 3i). The humanized mice were treated with 400 $\mathrm{mg} / \mathrm{kg}$ imatinib mesylate, $50 \mathrm{mg} / \mathrm{kg}$ MPA, or $25 \mathrm{mg} / \mathrm{kg}$ QNHC. 3 hours post-treatment, SARSCoV-2 pseudo-entry virus (1X10 4 FFU) was delivered by intra-xenograft inoculation. At 24 hpi, luciferase staining was detected in mice treated with vehicle. The number of $\mathrm{LUC}^{+}$cells was significantly decreased in mice treated with imatinib mesylate, MPA or QNHC (Fig. 3j, 3k).

Finally, hPSC-derived lung organoids pre-treated with $10 \mu \mathrm{M}$ imatinib, $3 \mu \mathrm{M}$ MPA or $4.5 \mu \mathrm{M}$ QNHC were infected with SARS-CoV-2 virus at MOI=0.5. At 24 hpi, qRT-PCR confirmed significantly decreased replicating viral RNA in lung organoids treated with imatinib, MPA or QNHC (Fig. 4a). Immunostaining confirmed a significant loss of SARS-CoV-2 $2^{+}$cells in imatinib, MPA or QNHC-treated hPSC derived-lung organoids (Fig. 4b). To determine the therapeutic 
potential of imatinib, MPA and QNHC, hPSC-derived lung organoids were infected with SARSCoV-2 virus $(\mathrm{MOI}=0.5)$. Three hours later, lung organoids were treated with $10 \mu \mathrm{M}$ imatinib, 3 $\mu \mathrm{M}$ MPA or $4.5 \mu \mathrm{M}$ QNHC. At 24 hpi, both viral RNA (Fig. 4c) and SARS-CoV-2 ${ }^{+}$cells (Fig. 4d) were significantly decreased in the lung organoids treated with each drug, highlighting the therapeutic potential. Transcriptional profiling was applied to compare DMSO and imatinibtreated lung organoids, and PCA plots showed these clustered separately (Fig. 4e). Volcano plots and GSEA analysis highlight the change of pathways caused by imatinib, related to fatty acid biosynthesis, steroid biosynthesis, fatty acid metabolism, and PPAR signaling pathway (Fig. 4f, 4g). Viruses have been known to target lipid signaling, synthesis, and metabolism to remodel their host cells into an optimal environment for their replication. Fatty acid is involved in multiple steps of viral circle, including membrane fusion during the entry process, virion envelopment during particle maturation, as well as virus replication ${ }^{21}$. The fact that fatty acid biosynthesis and metabolism pathways are changed in the imatinib-treated lung organoids suggests that imatinib might also affect virus replication and particle maturation. Finally, qRT-PCR and western blotting experiments confirmed the ability of imatinib to block anti-SARS-CoV-2 activity in Vero cells

\section{(Extended Data Fig. 4).}

The lung is the most vulnerable target organ for the SARS-CoV-2 virus, and respiratory failure is the primary disease outcome for COVID-19. Yet the primary model currently used for SARSCoV-2 studies are African green monkey kidney derived Vero cells, which have clear limitations for modeling complex human pulmonary or other organ systems. Therefore, the development of physiologically relevant human cell models to study SARS-CoV-2 infection is critically important. Here, we present an hPSC-derived lung organoid platform, including SP-B ${ }^{+}$AT2 cells that express 
ACE2 and TMPRSS2, two key factors involved in SARS-CoV-2 infection, which is consistent with the previous reports ${ }^{22}$. RNA-seq of infected organoids revealed upregulation of cytokine/chemokine signaling, which phenocopies the cytokine and chemokine changes observed in primary human COVID-19 pulmonary infection ${ }^{23}$. Finally, we used the hPSC-derived lung organoids in a high throughput screen for FDA-approved drugs. We identified several drugs that decreased the luciferase activity of SARS-CoV-2 pseudo-entry virus including imatinib, MPA and QNHC, both in vitro and in vivo. The anti-viral activity of these drugs was further validated against patient-derived SARS-CoV-2 virus.

Imatinib is an inhibitor of a number of tyrosine kinase enzymes, including Abl, c-kit, PDGF-R and others. Previous studies have also suggested imatinib as a potent inhibitor of SARS and MERS coronavirus fusion proteins ${ }^{24}$. Using HIV SARS-S and MERS-S pseudotyped virions, imatinib was shown to substantially block coronavirus $\mathrm{S}$ protein-induced fusion and prevent endosomal entry $^{25}$. Imatinib has been widely used to treat chronic myelogenous leukemia and other cancers, and should be considered for repurposing as a drug candidate for COVID-19 patients. Very recently, three clinical trials (ClinicalTrials.gov Identifier: NCT04346147, NCT04357613, NCT04356495) were registered to apply imatinib to treat COVID-19 patients. Our study provides experimental data to support these trials. 
bioRxiv preprint doi: https://doi.org/10.1101/2020.05.05.079095; this version posted May 5, 2020. The copyright holder for this preprint (which

Figure 1. was not certified by peer review) is the author/funder. All rights reserved. No reuse allowed without permission.

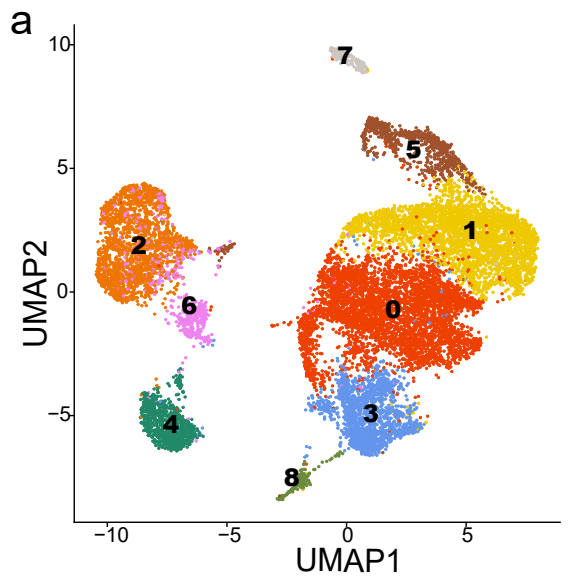

- 0 . AT1 cells

-1. AT2 cells

-2. Stromal cells_1

-3. Bronchiolar epithelial cells

-4. Stromal cells_2

-5. Proliferating cells

-6. Stromal cells_3

-7. Pulmonary neuroendocrine cells(PNEC)

-8. Airway epithelial cells
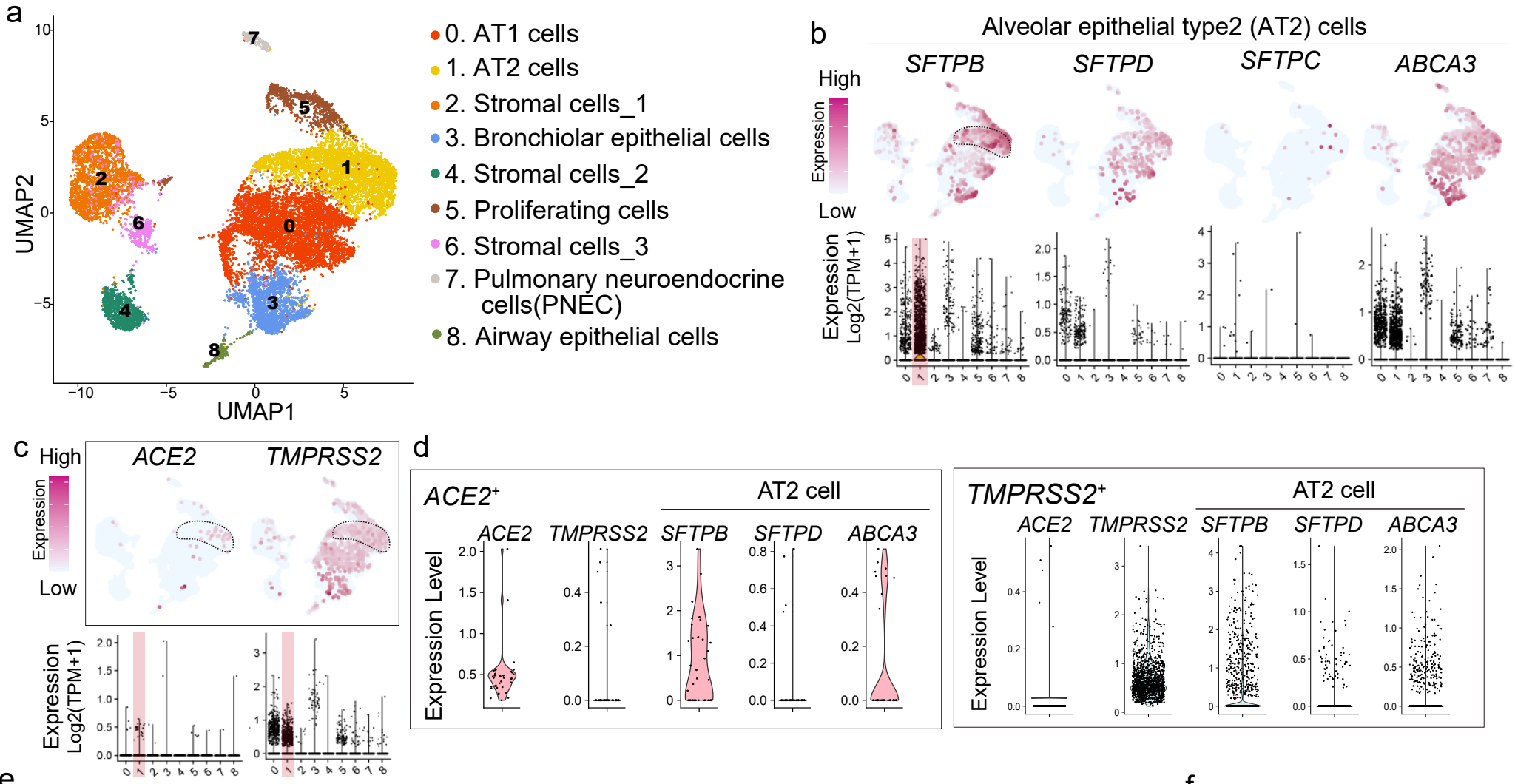

$\mathrm{d}$
ACE2 $^{+}$

e

SP-BACE2DAPI

ACE2
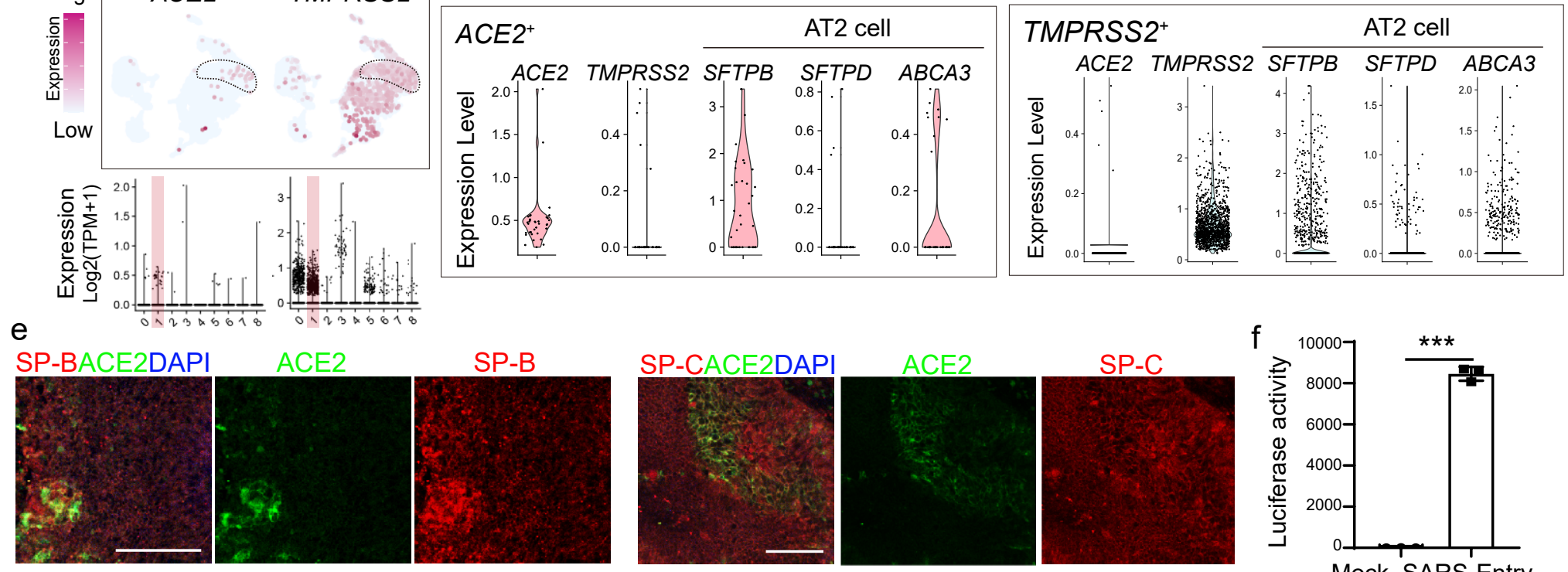

SP-B
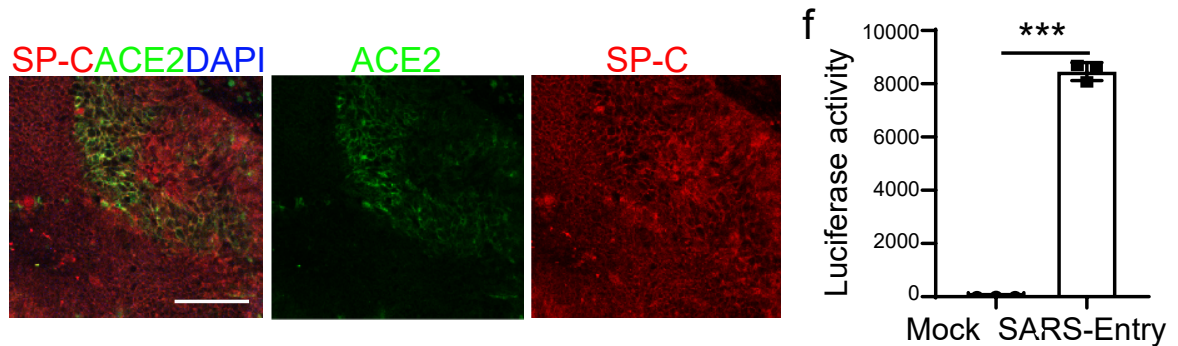

g
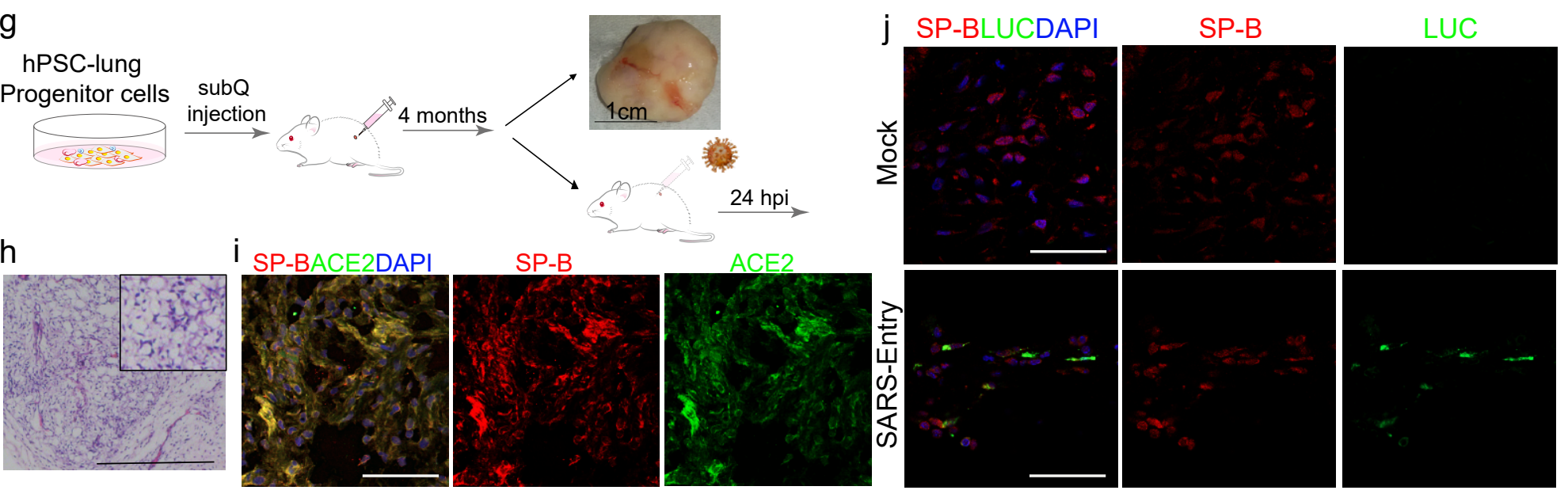


\section{Figure Legends.}

\section{Figure 1. hPSC-derived lung organoids express ACE2 and are permissive to SARS-CoV-2}

pseudo-entry virus infection both in vitro and in vivo. a. UMAP of hPSC-derived lung organoids, which contain 14,263 hPSC-derived lung epithelial cells (EPCAM ${ }^{+}$, UMI count $\left.>0\right)$, colored and annotated with clusters 0-8. AT2 cells, Alveolar Epithelial Type 2 cells. AT1 cells, Alveolar Epithelial Type 1 cells. b. Putative AT2 markers in each cluster in UMAPs. Relative expression level of each marker gene range from low (light blue) to high (pink) as indicated. Individual cells positive for lung cell markers are denoted by red dots. The violin plot shows the expression level $(\log 2(\mathrm{TPM}+1))$ of each indicated gene in each cluster. c. UMAP of $A C E 2$ and TMPRSS2 expression in AT2 cells. d. Violin plots of ACE2 and TMPRSS2 expression in cells expressing AT2 markers including $S F T P B, S F P T D$ and $A B C A 3$. e. Immunostaining of hPSC-derived lung organoids detected the co-expression of ACE2 in SP-B ${ }^{+}$or SP-C ${ }^{+}$AT2-like cells. Scale bars $=25$ $\mu \mathrm{m}$. f. Luciferase activity of hPSC-derived lung organoids either mock-infected or infected with SARS-CoV-2 pseudo-entry virus at 24 hpi $(\mathrm{MOI}=0.01)$. g. Schematic of the experimental flowchart for the mouse xenograft model formed with hPSC-derived lung cells. Briefly, the day 25 lung progenitor cells were injected subcutaneously in NSG mice and xenografts were collected after 4 months of transplantation. subQ injection, subcutaneous injection. The cells within the xenografts were isolated and analyzed by immunostaining and infection of SARS-CoV-2 pseudoentry virus. h, Representative image of Hematoxylin and Eosin staining on the xenograft lung tissue that shows the typical alveolar region. Scale Bars $=200 \mu \mathrm{m}$. i, Immunostaining of hPSCderived lung xenografts detected the expression of ACE2 in SP-B ${ }^{+}$cells. Scale bars $=25 \mu \mathrm{m} . \mathbf{j}$, Immunostaining of hPSC-derived lung xenografts at 24 hpi $\left(1 \times 10^{4}\right.$ FFU) detected the coexpression of luciferase (LUC) in SP-B ${ }^{+}$cells. Scale bars $=25 \mu \mathrm{m}$. Data was presented as mean \pm 
bioRxiv preprint doi: https://doi.org/10.1101/2020.05.05.079095; this version posted May 5, 2020. The copyright holder for this preprint (which was not certified by peer review) is the author/funder. All rights reserved. No reuse allowed without permission.

STDEV. $P$ values were calculated by unpaired two-tailed Student's t test. ${ }^{*} P<0.05, * * P<0.01$, and $* * * P<0.001$. 


\section{Figure 2}
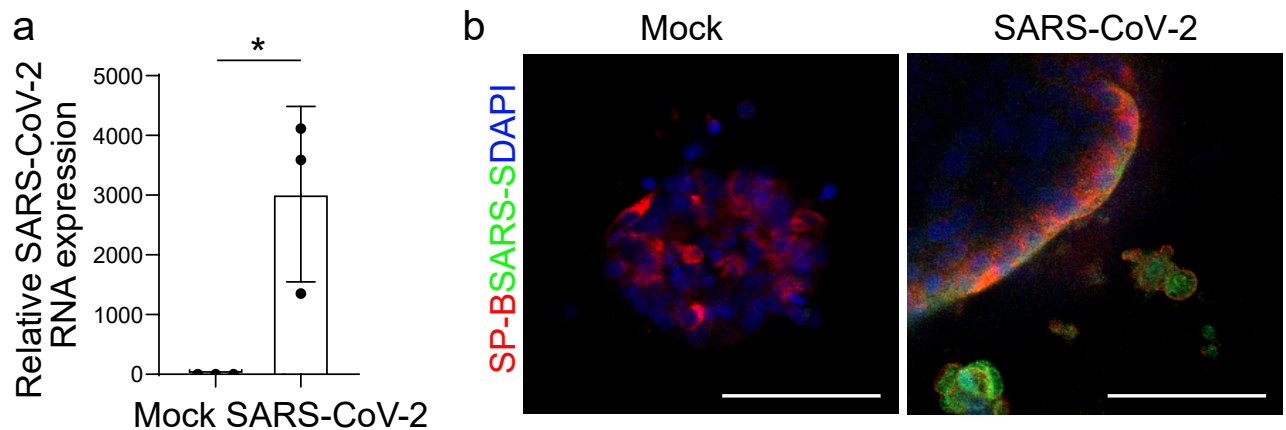

C

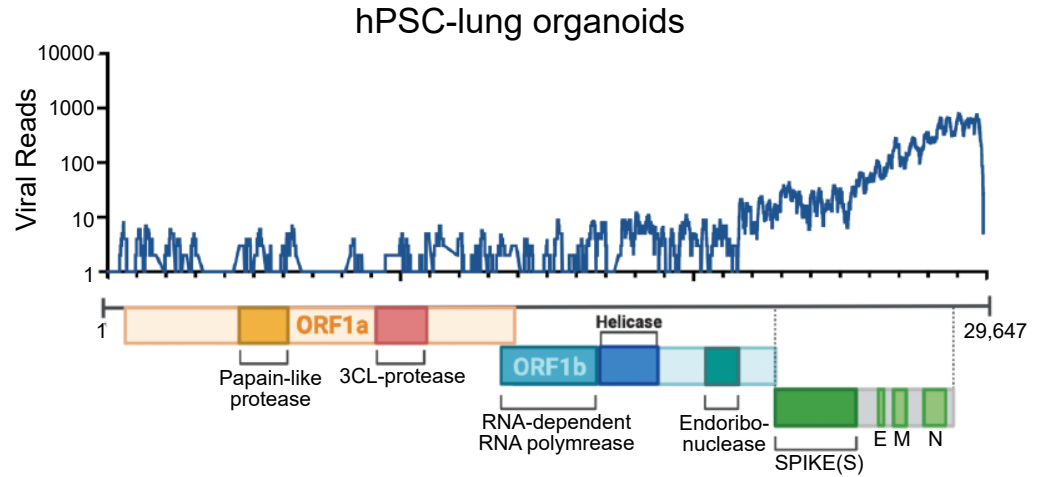

d

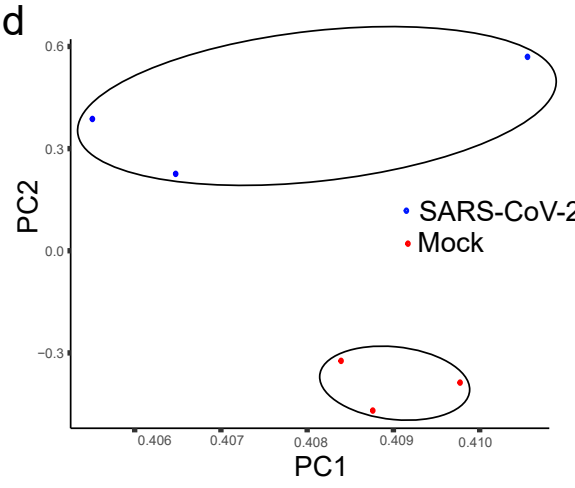

e
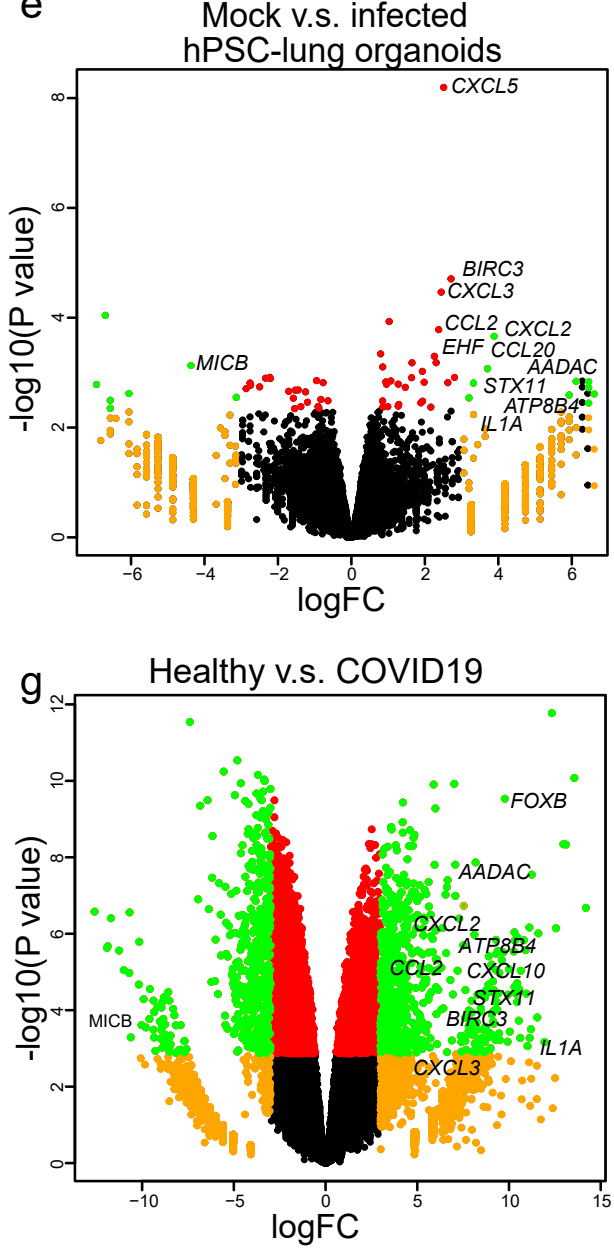

f

Mock v.s. infected hPSC-lung organoids

Rheumatoid arthritis TNF signaling pathway Legionellosis Malaria

IL-17 signaling pathway Leishmaniasis AGE-RAGE signaling pathway Chemokine signaling pathway Kaposi sarcoma-associated herpesvirus infection Cytokine-cytokine receptor interaction

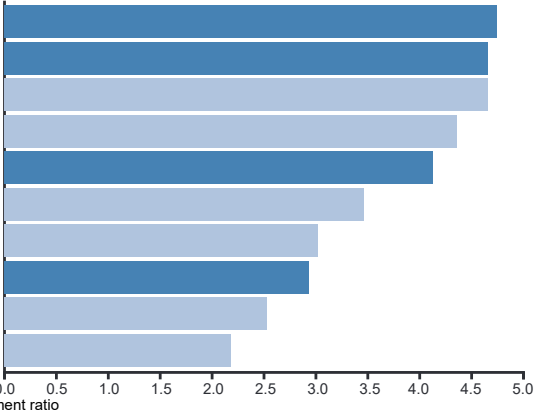

$\mathrm{h}$

\section{Healthy v.s. COVID19}

Longevity regulating pathway IL-17 signaling pathway

Estrogen signaling pathway Pathogenic Escherichia coli infection Fluid shear stress and atherosclerosis Bacterial invasion of epithelial cells Prostate cancer

FoxO signaling pathway Regulation of actin cytoskeleton Pathways in cancer

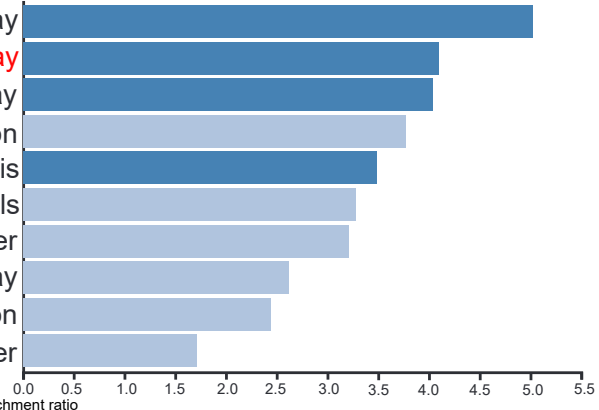


Figure 2. Transcriptomic analysis of SARS-CoV-2 infected hPSC-derived lung organoids demonstrates robust SARS-CoV-2 replication, upregulation of chemokine expression with no upregulation of Type I/III IFN signaling. a, Relative SARS-CoV-2 R viral NA expression in hPSC-derived lung organoids. Total viral RNA from infected hPSC-derived lung organoids $(\mathrm{MOI}=0.01)$ was analyzed by qRT-PCR for the presence of N sgRNA transcripts relative to ACTB. b, Immunostaining of hPSC-derived lung organoids at 24 hpi (SARS-CoV-2, MOI=0.01) detected the expression of SARS-S in SP-B ${ }^{+}$cells. Scale bars $=25 \mu \mathrm{m}$. c, Alignment of the transcriptome with the viral genome in SARS-CoV-2 infected hPSC-derived lung organoids. Schematic below shows the SARS-CoV-2 genome. d, PCA plot of mock-infected or SARS-CoV-2 infected hPSCderived lung organoids. e, Volcano plot analysis of differential expression of SARS-CoV-2 infected hPSC-derived lung organoids versus mock infection. Individual genes are denoted by gene name. f, Gene over-representation analysis on KEGG pathway database of SARS-CoV-2 infected hPSC-derived lung organoids versus mock infection. g, Volcano plot analysis of differential expression of lung biopsy from COVID-19 versus healthy patients. Individual genes are denoted by gene name. h. Gene over-representation analysis on KEGG pathway database of lung biopsy from COVID-19 versus healthy patients (GSE147507) $)^{23}$.

Data was presented as mean \pm STDEV. $P$ values were calculated by unpaired two-tailed Student's t test. $* P<0.05, * * P<0.01$, and $* * * P<0.001$. 
Figure 3
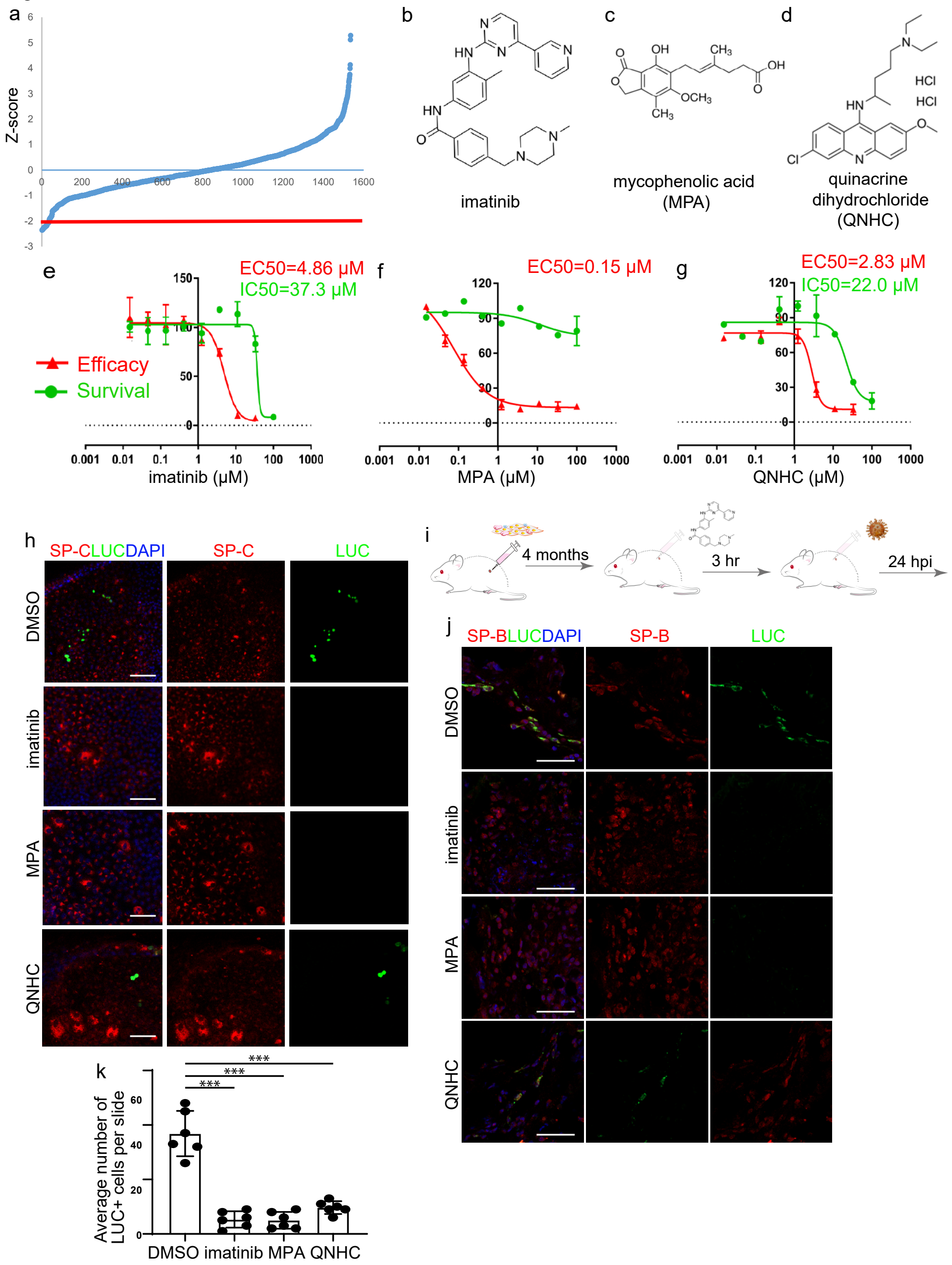
Figure 3. A hPSC-derived lung organoid-based high throughput chemical screen identifies three FDA-approved drug candidates that block SARS-CoV-2 entry. a, Primary screening results. b-d, Chemical structure of imatinib (b), mycophenolic acid (MPA, c), and quinacrine dihydrochloride (QNHC, d). e-g, Efficacy and toxicity curves of imatinib (e), MPA (f), and QNHC (g). Data is presented as mean \pm STDEV. $\mathrm{N}=3 . \mathbf{h}$, Immunostaining of $\mathrm{LUC}^{+}$cells in imatinib, MPA, and QNHC-treated hPSC-derived lung organoids at 24 hpi $(\mathrm{MOI}=0.01)$. Scale bar $=25 \mu \mathrm{m}$. i, Scheme of in vivo drug treatment. j-k, Immunostaining (j) and quantification (k) of hPSC-derived lung xenografts of mice treated with $400 \mathrm{mg} / \mathrm{kg}$ imatinib, $50 \mathrm{mg} / \mathrm{kg} \mathrm{MPA}$, and $25 \mathrm{mg} / \mathrm{kg}$ QNHC at 24 hpi $\left(1 \mathrm{X} 10^{4} \mathrm{FFU}\right)$. Scale bars $=25 \mu \mathrm{m} . \mathrm{N}=6$ xenografts per condition 5 slides per xenograft. Data was presented as mean \pm STDEV. $P$ values were calculated by unpaired two-tailed Student's t test. $* P<0.05, * * P<0.01$, and $* * * P<0.001$ 
Figure 4
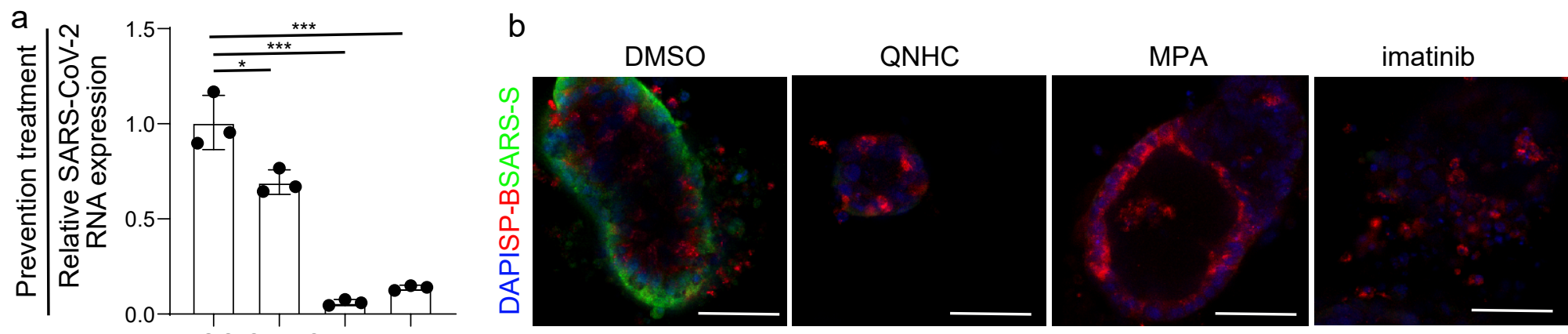

DMSO QNHC MPA imatinib

C

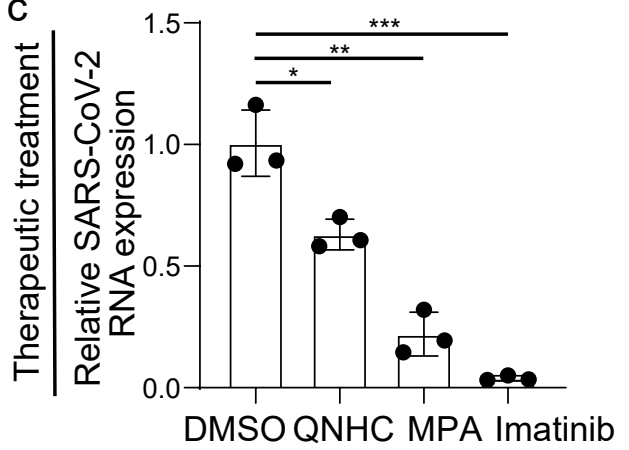

d

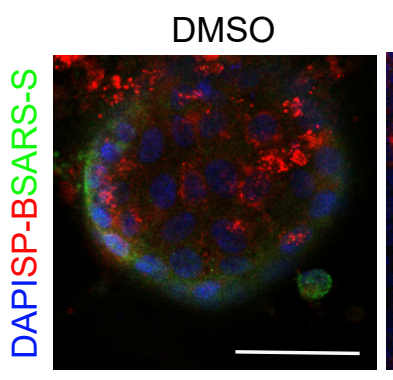

QNHC

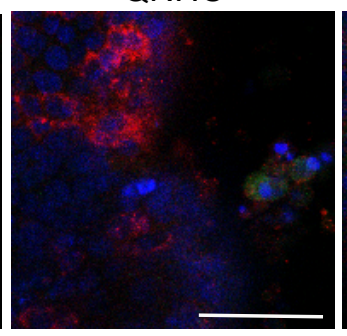

MPA

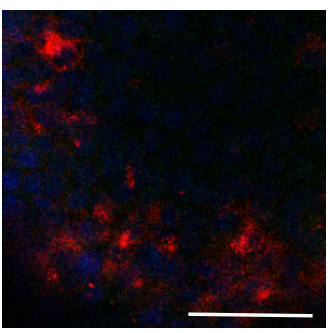

imatinib

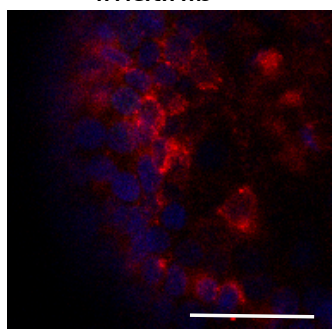

g

Fatty acid biosynthesis

Spliceosome

Steroid biosynthesis

Protein export

Fatty acid metabolism

Ribosome

PPAR signaling pathway

Pathogenic Escherichia coli infection

Ribosome biogenesis in eukaryotes

RNA transport

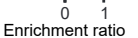


Figure 4. Imatinib, mycophenolic acid, and quinacrine dihydrochloride each block the entry and spreading of SARS-CoV-2 virus. a, Relative SARS-CoV-2 viral RNA expression in hPSCderived lung organoids pre-treated with $10 \mu \mathrm{M}$ imatinib, $3 \mu \mathrm{M}$ MPA or $4.5 \mu \mathrm{M}$ QNHC at 24 hpi of SARS-CoV-2 virus (MOI=0.5). Total viral RNA from infected hPSC-derived lung organoids $(\mathrm{MOI}=0.01)$ was analyzed by qRT-PCR for the presence of N sgRNA transcripts relative to ACTB. b, Immunostaining of SARS-CoV-2 Spike protein (SARS-S) and SP-B in imatinib, MPA, or QNHC treated hPSC-derived lung organoids at 24 hpi $(\mathrm{MOI}=0.5)$. Scale bars $=25 \mu \mathrm{m}$. c, Relative SARS-CoV-2 viral RNA expression at 24 hpi of hPSC-derived lung organoids infected with SARS-CoV-2 virus $(\mathrm{MOI}=0.5)$ and three hours later followed by $10 \mu \mathrm{M}$ imatinib, $3 \mu \mathrm{M}$ MPA or 4.5 $\mu \mathrm{M}$ QNHC treatment. Total RNA from infected hPSC-derived lung organoids $(\mathrm{MOI}=0.5)$ was analyzed by qRT-PCR for the presence of $\mathrm{N}$ sgRNA transcripts relative to ACTB. d, Immunostaining of SARS-S and SP-B at 24 hpi of hPSC-derived lung organoids infected with SARS-CoV-2 virus $(\mathrm{MOI}=0.5)$ and three hours later followed by $10 \mu \mathrm{M}$ imatinib, $3 \mu \mathrm{M}$ MPA or 4.5 $\mu \mathrm{M}$ QNHC treatment. Scale bars $=100 \mu \mathrm{m}$. e, PCA plot of hPSC-derived lung organoids pretreated with DMSO or $10 \mu \mathrm{M}$ imatinib at 24 hpi of SARS-CoV-2 virus. f, Volcano plot analysis of differential expression of hPSC-derived lung organoids pretreated with DMSO or $10 \mu \mathrm{M}$ imatinib at 24 hpi of SARS-CoV-2 virus. Individual genes are denoted by gene name. g, Gene over-representation analysis on KEGG pathway database of differential expression of hPSCderived lung organoids pretreated with DMSO or $10 \mu \mathrm{M}$ imatinib at 24 hpi of SARS-CoV-2 virus. Data was presented as mean \pm STDEV. $P$ values were calculated by unpaired two-tailed Student's t test. $* P<0.05, * * P<0.01$, and $* * * P<0.001$. 


\section{Extended Data Figure 1.}

Lung organoids

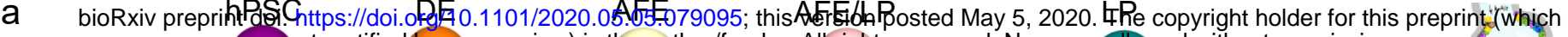

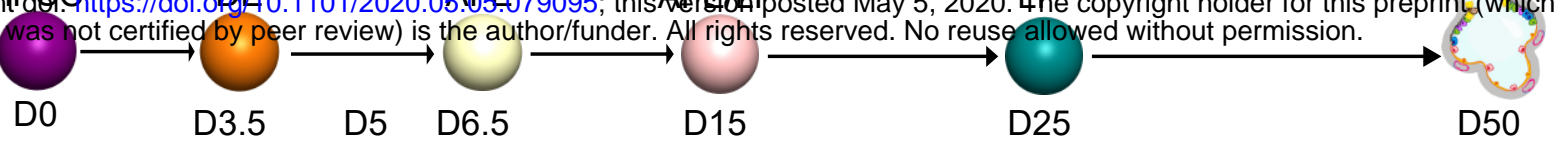

Basal medium

\begin{tabular}{lcc} 
IMDM/F12 & \multicolumn{2}{c}{ IMDM/F12 } \\
Activin A & DSM & IWP2 \\
Y-27632 & SB & SB \\
BMP4 & & \\
bFGF & &
\end{tabular}

IMDM/F12

IMDM/F12

IMDM/F12

GF+chemicals

CHIR
BMP4
FGF10
KGF
RA

CHIR

FGF10

CHIR

KGF

FGF10

KGF

$\mathrm{DCl}$

DAPT
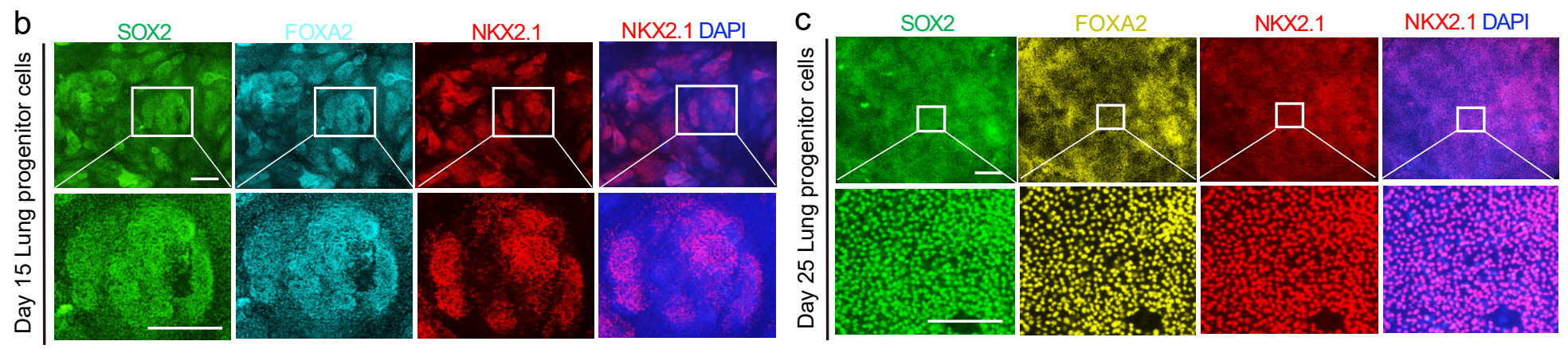


\section{Extended Data.}

Extended Data Figure 1. Directed differentiation of hPSC toward lung organoids. a, Scheme of directed differentiation of hPSCs to lung organoids. b, $\mathbf{c}$ Immunostaining was performed in the hPSC-derived cell cultures at day 15 (b) and day 25 (c). Scale bars $=100 \mu \mathrm{m}$. 


\section{Extended Data Figure 2}

bioRxiv preprint doi: https://doi.org/10.1101/2020.05.05.079095; this version posted May 5, 2020. The copyright holder for this preprint (which Express
2
1
-0
-1
-2 was not certified by peer review) is the author/funderball rights reserved. No reuse allowed without permission.

Alveolar epithelial type1 (AT1) cells

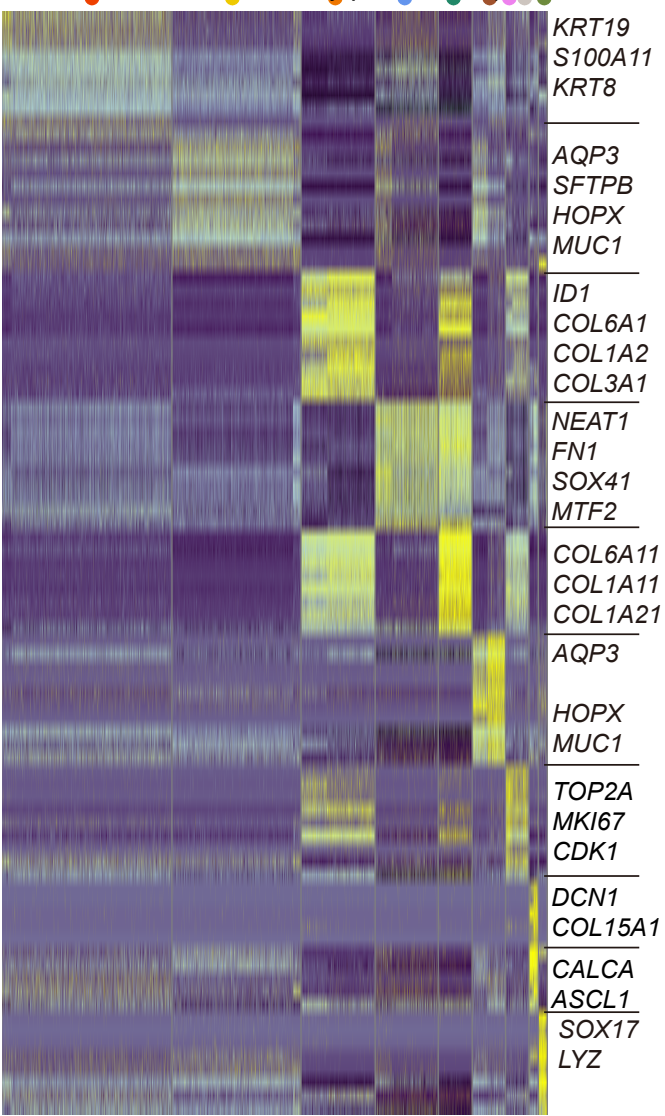

0. AT1 cells

1. AT2 cells

2. Stromal cells_1

- 3. Bronchiolar epithelial cells

- 4. Stromal cells_2

- 5. Proliferating cells

6. Stromal cells_3

7. Pulmonary neuroendocrine cells(PNEC)

- 8. Airway epithelial cells
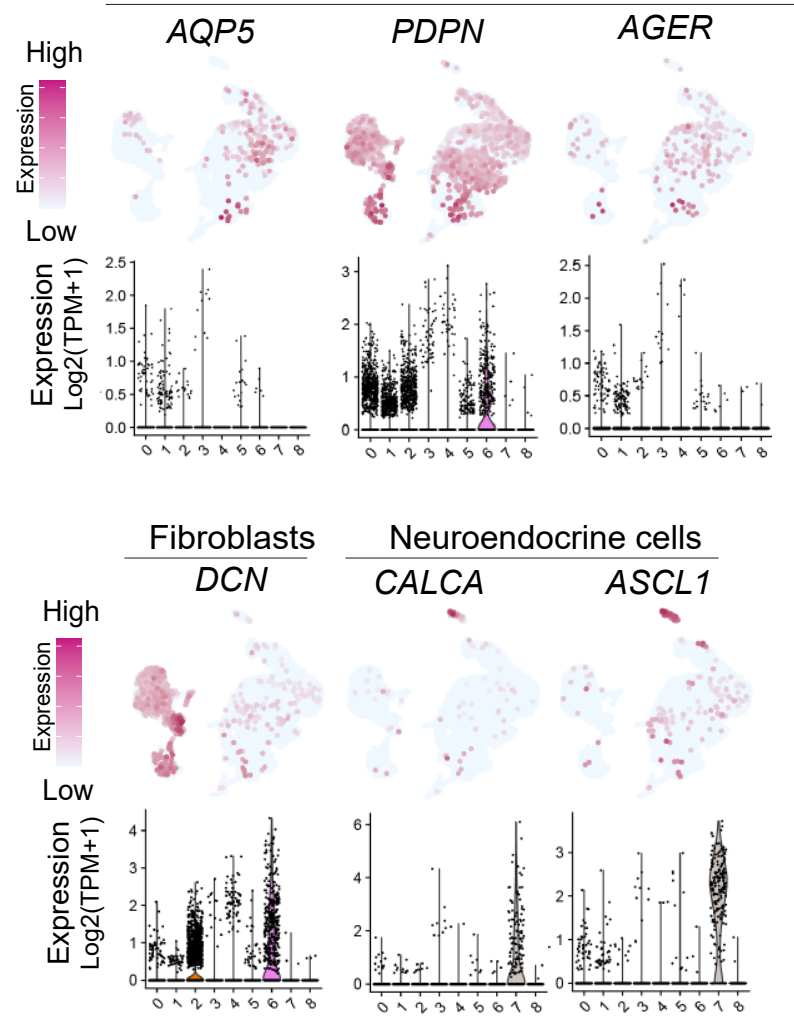
Extended Data Figure 2. Single cell RNA-seq analysis of hPSC-derived lung organoids. a, Heatmap of enriched genes in each cluster of scRNA profiles in hPSC-derived lung organoids. Each row represents one top differentially expressed gene and each column represents a single cell. b. Putative AT1, fibroblast and PNECs markers in each cluster in UMAPs. Relative expression of each marker gene range from low (light blue) to high (pink) as indicated. Individual cells positive for lung cell markers are donated by red dots. The violin plot shows the expression level $(\log 2(\mathrm{TPM}+1))$ of indicated gene in each cluster. 


\section{Extended Data Figure 3}

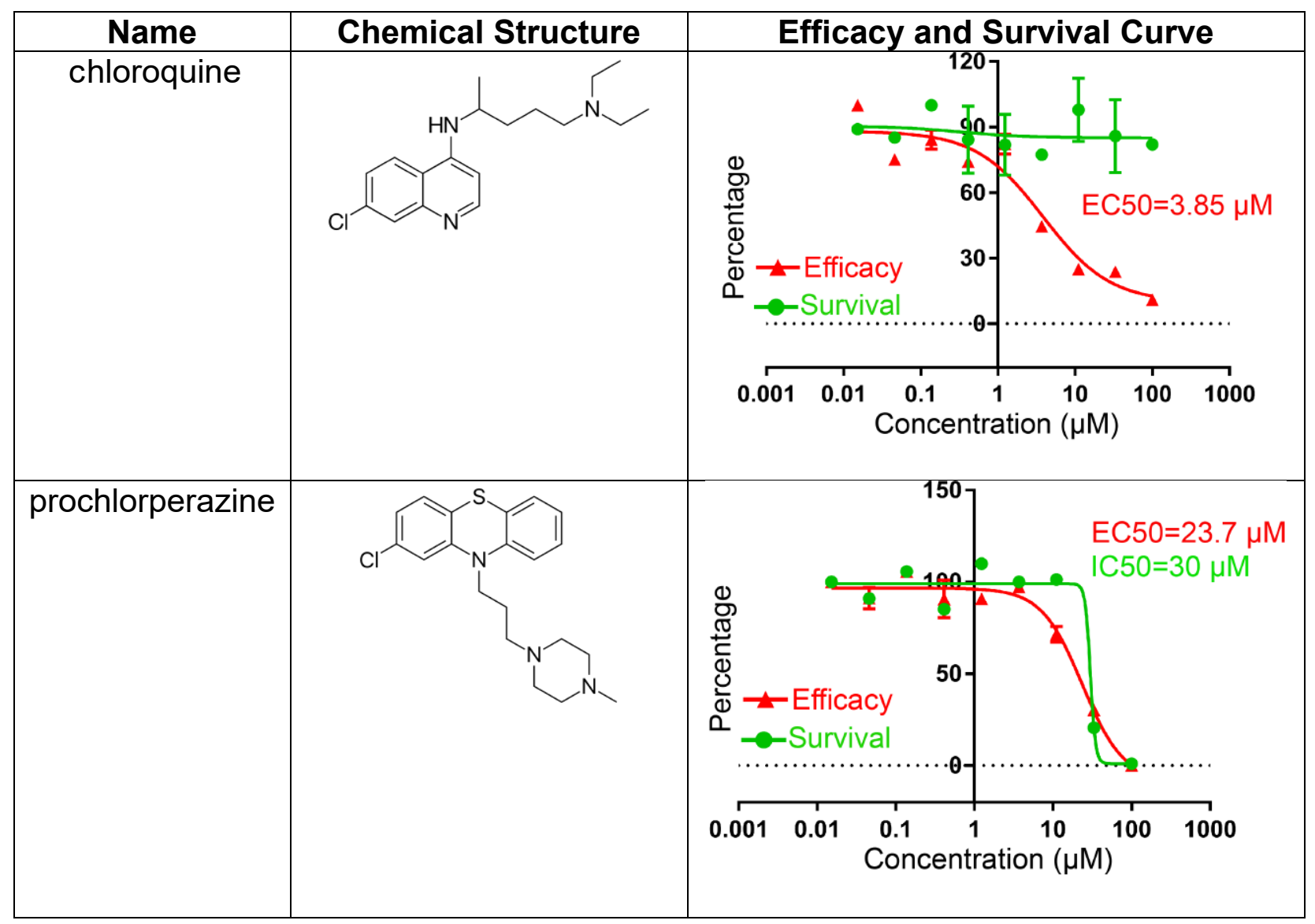


bioRxiv preprint doi: https://doi.org/10.1101/2020.05.05.079095; this version posted May 5, 2020. The copyright holder for this preprint (which was not certified by peer review) is the author/funder. All rights reserved. No reuse allowed without permission.

Extended Data Figure 3. Chemical structure, efficacy curve and toxicity curve of primary hit drug candidates. 
bioRxiv preprint doi: https://doi.org/10.1101/2020.05.05.079095; this version posted May 5, 2020. The copyright holder for this preprint (which was not certified by peer review) is the author/funder. All rights reserved. No reuse allowed without permission.

\section{Extended Data Figure 4}

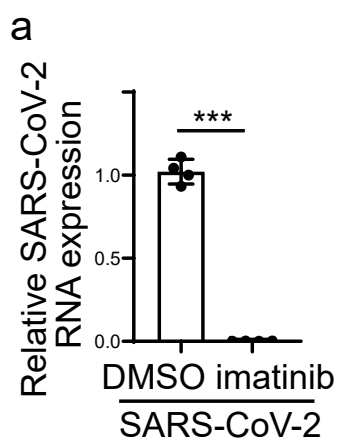

b

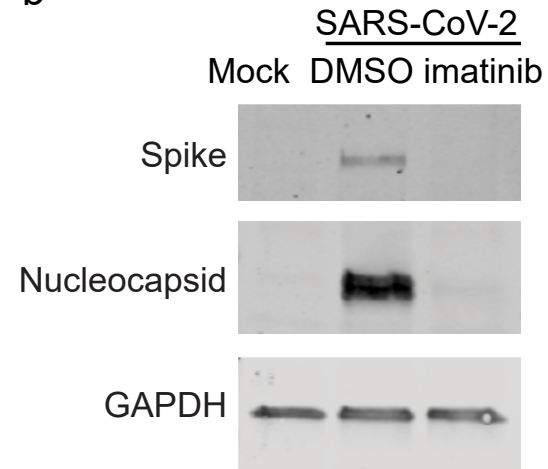

C

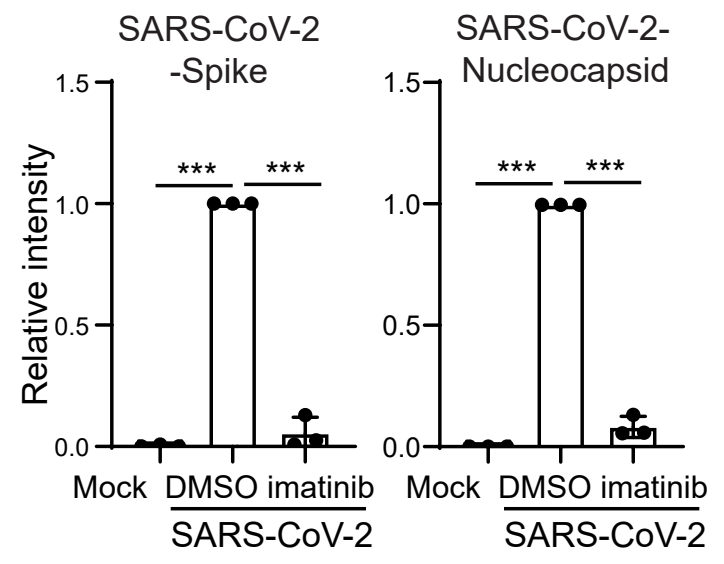


Extended Data Figure 4. Imatinib shows anti-SARS-CoV-2 activity on Vero cells. a, qRTPCR analysis of DMSO or $10 \mu \mathrm{M}$ imatinib treated Vero cells at $24 \mathrm{hpi}(\mathrm{SARS}-\mathrm{CoV}-2, \mathrm{MOI}=0.01$ ). Data was presented as mean \pm STDEV. $P$ values were calculated by unpaired two-tailed Student's t test. $* P<0.05,{ }^{*} P<0.01$, and $* * * P<0.001$. b, c, Western blotting (b) and quantification (c) of DMSO or $10 \mu \mathrm{M}$ imatinib treated Vero cells at 24 hpi (SARS-CoV-2, MOI=0.01). 


\section{Methods.}

\section{hPSC lung differentiation.}

Protocols for maintenance of hPSCs and generation of lung cells were slightly modified from previous studies ${ }^{4,15}$. The hESC line RUES2 was cultured on irradiated mouse embryonic fibroblasts (Global Stem, cat. no. GSC-6001G) at a density of $20,000-25,000$ cells $/ \mathrm{cm}^{2}$ in a medium of DMEM/F12, 20\% knockout serum replacement (Life Technologies), $0.1 \mathrm{mM} \beta$ mercaptoethanol (Sigma Aldrich) and 20 ng/ml bFGF (R\&D Systems), and medium was changed daily. hESC cultures were maintained in an undifferentiated state at $37{ }^{\circ} \mathrm{C}$ in a $5 \% \mathrm{CO} 2 /$ air environment until stem cells reached about $90 \%$ confluence.

hESC differentiation into endoderm was performed in serum-free differentiation (SFD) medium of DMEM/F12 (3:1) (Life Technologies) supplemented with N2 (Life Technologies), B27, 50 $\mu \mathrm{g} / \mathrm{ml}$ ascorbic acid, $2 \mathrm{mM}$ Glutamax, $0.4 \mu \mathrm{M}$ monothioglycerol, $0.05 \% \mathrm{BSA}$ at $37{ }^{\circ} \mathrm{C}$ in a $5 \%$ $\mathrm{CO} 2 / 5 \% \mathrm{O} 2 / 95 \% \mathrm{~N} 2$ environment. hESCs were treated with Accutase and plated onto low attachment 6-well plates (Corning Incorporated, Tewksbury MA), resuspended in endoderm induction medium containing $10 \mu \mathrm{M}$ Y-27632, $0.5 \mathrm{ng} / \mathrm{ml}$ human BMP-4, $2.5 \mathrm{ng} / \mathrm{ml}$ human bFGF, $100 \mathrm{ng} / \mathrm{ml}$ human Activin A, for 72-84 hours dependent on the formation rates of endoderm cells. On day 3 or 3.5 , the endoderm bodies were dissociated into single cells using $0.05 \%$ Trypsin $/ 0.02 \%$ EDTA and plated onto fibronectin-coated, 24-well tissue culture plates $(\sim 100,000-150,000$ cells/well). For induction of anterior foregut endoderm, the endoderm cells were cultured in SFD medium supplemented with $1.5 \mu \mathrm{M}$ dorsomorphin dihydrochloride (R\&D Systems) and $10 \mu \mathrm{M}$ SB431542 (R\&D Systems) for 36-48 h, and then switched to 36-48 h of $10 \mu \mathrm{M}$ SB431542 and 1 
$\mu \mathrm{M}$ IWP2 (R\&D Systems) treatment. For induction of early stage lung progenitor cells (day 615), the resulting anterior foregut endoderm was treated with $3 \mu \mathrm{M}$ CHIR99021, $10 \mathrm{ng} / \mathrm{ml}$ human FGF10, $10 \mathrm{ng} / \mathrm{ml}$ human FGF-7, $10 \mathrm{ng} / \mathrm{ml}$ human BMP-4 and 50-60 nM all-trans retinoic acid (ATRA), in SFD medium for 8-10 d. The day 10-15 cultures were maintained in a 5\% CO2/air environment. On days 15 and 16, the lung field progenitor cells were replated after one minute trypsinization onto fibronectin-coated plates, in the presence of SFD containing either a combination of five factors ( $3 \mu \mathrm{M}$ CHIR99021, $10 \mathrm{ng} / \mathrm{ml}$ human FGF10, $10 \mathrm{ng} / \mathrm{ml}$ human FGF7, $10 \mathrm{ng} / \mathrm{ml}$ human BMP-4, and $50 \mathrm{nM}$ ATRA), or three factors (3 $\mu$ M CHIR99021, $10 \mathrm{ng} / \mathrm{ml}$ human FGF10, $10 \mathrm{ng} / \mathrm{ml}$ human FGF7) for day 14-16. Day 16-25 cultures of late stage lung progenitor cells were maintained in SFD media containing $3 \mu \mathrm{M}$ CHIR99021, $10 \mathrm{ng} / \mathrm{ml}$ human FGF10, 10 ng/ml human FGF7, in a 5\% $\mathrm{CO}_{2} /$ air environment. For differentiation of mature lung cells (day 25 to 55), cultures were re-plated after brief trypsinization onto 3.3\% Matrigel-coated 24-well plates in SFD media containing maturation components containing $3 \mu \mathrm{M}$ CHIR99021, $10 \mathrm{ng} / \mathrm{ml}$ human FGF-10; $10 \mathrm{ng} / \mathrm{ml}$ human FGF7, and DCI (50 nM Dexamethasone, $0.1 \mathrm{mM}$ 8-bromo-cAMP (Sigma Aldrich ) and 0.1 mM IBMX (3,7-dihydro-1-methyl-3-(2-methylpropyl)-1H-purine-2,6dione) (Sigma Aldrich)). $1 \mu \mathrm{M}$ DAPT was added to the maturation media for induction of pulmonary neuroendocrine cells (PNECs) and Tuft cells. The protocol details are summarized in Figure S1A.

\section{Cell Lines.}

HEK293T (human [Homo sapiens] fetal kidney) and Vero E6 (African green monkey [Chlorocebus aethiops] kidney) were obtained from ATCC (https://www.atcc.org/). Cells were 
cultured in Dulbecco's Modified Eagle Medium (DMEM) supplemented with 10\% FBS and 100 I.U./mL penicillin and $100 \mu \mathrm{g} / \mathrm{mL}$ streptomycin. All cell lines were incubated at $37^{\circ} \mathrm{C}$ with $5 \%$ $\mathrm{CO}_{2}$.

\section{SARS-CoV-2-Pseudo-Entry Viruses.}

Recombinant Indiana VSV (rVSV) expressing SARS-CoV-2 spikes was generated as previously described $18,19,26$. HEK293T cells were grown to $80 \%$ confluency before transfection with pCMV3-SARS-CoV2-spike (kindly provided by Dr. Peihui Wang, Shandong University, China) using FuGENE 6 (Promega). Cells were cultured overnight at $37^{\circ} \mathrm{C}$ with $5 \% \mathrm{CO}$. The next day, the media was removed and VSV-G pseudotyped $\Delta \mathrm{G}$-luciferase ( $\mathrm{G}^{*} \Delta \mathrm{G}$-luciferase, Kerafast) was used to infect the cells in DMEM at an MOI of 3 for $1 \mathrm{hr}$ before washing the cells with 1X DPBS three times. DMEM supplemented with $2 \%$ FBS and 100 I.U. $/ \mathrm{mL}$ penicillin and $100 \mu \mathrm{g} / \mathrm{mL}$ streptomycin was added to the infected cells and they were cultured overnight as described above. The next day, the supernatant was harvested and clarified by centrifugation at $300 \mathrm{xg}$ for $10 \mathrm{~min}$ before aliquoting and storing at $-80^{\circ} \mathrm{C}$.

\section{SARS-CoV-2 Viruses.}

SARS-CoV-2, isolate USA-WA1/2020 (NR-52281) was deposited by the Center for Disease Control and Prevention and obtained through BEI Resources, NIAID, NIH. SARS-CoV-2 was propagated in Vero E6 cells in DMEM supplemented with 2\% FBS, 4.5 g/L D-glucose, 4 mM Lglutamine, $10 \mathrm{mM}$ Non-Essential Amino Acids, $1 \mathrm{mM}$ Sodium Pyruvate and $10 \mathrm{mM}$ HEPES as described previously ${ }^{23}$. 
All work involving live SARS-CoV-2 was performed in the CDC/USDA-approved BSL-3 facility

of the Global Health and Emerging Pathogens Institute at the Icahn School of Medicine at Mount Sinai in accordance with institutional biosafety requirements

\section{SARS-CoV-2 entry virus infections.}

For lung organoids, organoids were seeded in 24-well plates, pseudo-typed virus was added for $\mathrm{MOI}=0.01$ and centrifuged the plate at $1200 \mathrm{~g}, 1$ hour. At $24 \mathrm{hpi}$, organoids were fixed for immunohistochemistry or harvested for luciferase assay following the Luciferase Assay System protocol (E1501, Promega)

\section{SARS-CoV-2 virus infections.}

hESC-derived lung organoids were infected with SARS-CoV-2 at the indicated MOI and incubated for $24 \mathrm{~h}$ at $37^{\circ} \mathrm{C}$. Where indicated, hESC-derived lung organoids were pretreated with DMSO, $10 \mu \mathrm{M}$ imatinib, $3 \mu \mathrm{M}$ MPA or $4.5 \mu \mathrm{M}$ QNHC for $3 \mathrm{~h}$ prior to infection as well as during the course of infection. Where indicated, hESC-derived lung organoids were treated with DMSO, $10 \mu \mathrm{M}$ imatinib, $3 \mu \mathrm{M}$ MPA or $4.5 \mu \mathrm{M}$ QNHC 3 hpi. At the time point of harvest, cells were washed three times with PBS and harvested for either RNA analysis or immunofluorescence staining.

Approximately $2.5 \times 105$ Vero E6 cells were pre-treated with DMSO, $10 \mu \mathrm{M}$ imatinib, $3 \mu \mathrm{M}$ MPA or 4.5 $\mu \mathrm{M}$ QNHC for $1 \mathrm{~h}$ prior to infection with SARS-CoV-2 at an MOI of 0.01 in DMEM supplemented with 2\% FBS, $4.5 \mathrm{~g} / \mathrm{L}$ D-glucose, 4 mM L-glutamine, $10 \mathrm{mM}$ Non-Essential Amino 
Acids, 1 mM Sodium Pyruvate and 10 mM HEPES. At 24 hpi, cells were washed three times with PBS before harvesting for RNA or protein analysis.

Cells were either lysed in TRIzol for RNA analysis or in RIPA buffer for protein analysis or fixed in 5\% formaldehyde for $24 \mathrm{~h}$ for immunofluorescent staining, prior to safe removal from the BSL3 facility.

\section{Xenograft formation.}

1 million hESC-derived cells at lung progenitor stage (at day 25) were subcutaneously injected into 6-8 weeks old NOD.Cg-Prkdcscid Il2rgtm $1 \mathrm{WjI} / \mathrm{SzJ}$ (NSG) mice (Jackson Laboratory, Bar Harbor, Maine). When xenograft size becomes 1-2 $\mathrm{CM}^{3}$, they were sacrificed immediately, necropsy performed, and cells were harvested for further histological or molecular study.

\section{Immunohistochemistry.}

Histology on tissues from mice was performed on paraffin-embedded or frozen sections from xenografts and corresponding normal tissues as previously described ${ }^{27}$. Tissues were fixed overnight in $10 \%$ buffered formalin and transferred to $70 \%$ ethanol, followed by paraffin embedding, or tissues were fixed in $10 \%$ buffered formalin and transferred to $30 \%$ sucrose, followed by snap frozen in O.C.T (Fisher Scientific, Pittsburgh, PA). Adjacent sections stained with Hematoxylin and Eosin were used for comparison. Living cells in culture were directly fixed in 4\% paraformaldehyde for $25 \mathrm{~min}$, followed with $15 \mathrm{~min}$ permeabilization in $0.1 \%$ Triton X-100.

For immunofluorescence, cells or tissue sections were immunostained with primary antibodies at 
$4^{\circ} \mathrm{C}$ overnight and secondary antibodies at RT for $1 \mathrm{~h}$. The information for primary antibodies and secondary antibodies are provided in Table S3. Nuclei were counterstained by DAPI.

\section{Western blot.}

Protein was extracted from cells in Radioimmunoprecipitation assay (RIPA) lysis buffer containing 1X Complete Protease Inhibitor Cocktail (Roche) and 1X Phenylmethylsulfonyl fluoride (Sigma Aldrich) prior to safe removal from the BSL-3 facility. Samples were analysed by SDS-PAGE and transferred onto nitrocellulose membranes. Proteins were detected using rabbit polyclonal anti-GAPDH (Sigma Aldrich, G9545), mouse monoclonal anti-SARS-CoV-2 Nucleocapsid [1C7] and mouse monoclonal anti-SARS-CoV-2 Spike [2B3E5] protein (a kind gift by Dr. T. Moran, Center for Therapeutic Antibody Discovery at the Icahn School of Medicine at Mount Sinai). Primary antibodies were detected using Fluorophore-conjugated secondary goat anti-mouse (IRDye 680RD, 926-68070) and goat anti-rabbit (IRDye 800CW, 926-32211) antibodies. Antibody-mediated fluorescence was detected on a LI-COR Odyssey CLx imaging system and analyzed using Image Studio software (LI-COR).

\section{qRT-PCR.}

Total RNA samples were prepared from cells/organoids using TRIzol and Direct-zol RNA Miniprep Plus kit (Zymo Research) according to the manufacturer's instructions. To quantify viral replication, measured by the expression of sgRNA transcription of the viral $\mathrm{N}$ gene, one-step quantitative real-time PCR was performed using SuperScript III Platinum SYBR Green One-Step qRT-PCR Kit (Invitrogen) with primers specific for the TRS-L and TRS-B sites for the N gene as 
well as ACTB as an internal reference. Quantitative real-time PCR reactions were performed on a LightCycler 480 Instrument II (Roche). Delta-delta-cycle threshold $(\Delta \Delta \mathrm{CT})$ was determined relative to the ACTB and mock infected /treated samples. Error bars indicate the standard deviation of the mean from three biological replicates. The sequences of primers/probes are provided in Table S4.

\section{Single-cell RNA-seq data analysis.}

We filtered cells with less than 200 or more than 6000 genes detected as well as cells with mitochondria gene content greater than $30 \%$, and used the remaining 14263 cells for downstream analysis. We normalized the gene expression UMI counts using a deconvolution strategy implemented by the R scran package (v.1.14.1). In particular, we pre-clustered cells using the quickCluster function; we computed size factor per cell within each cluster and rescaled the size factors by normalization between clusters using the computeSumFactors function; and we normalized the UMI counts per cell by the size factors and took a logarithm transform using the normalize function. We identified highly variable genes using the FindVariableFeatures function in the R Seurat (v3.1.0) ${ }^{28}$, and selected the top 3000 variable genes after excluding mitochondria genes, ribosomal genes and dissociation-related genes. The list of dissociation-related genes was originally built on mouse data ${ }^{29}$; we converted them to human ortholog genes using Ensembl BioMart. We scaled the normalized counts and performed PCA on the highly variable genes using the ScaleData and RunPCA functions in the R Seurat package ${ }^{28}$. We selected the top 20 PCs for downstream visualization and clustering analysis. We ran UMAP dimensional reduction using the RunUMAP function in the R Seurat package with the number of neighboring points setting to 35 and training epochs setting to 500. We clustered cells into fifteen clusters by constructing a shared 
nearest neighbor graph and then grouping cells of similar transcriptome profiles using the FindNeighbors function and FindClusters function (resolution set to 0.2) in the R Seurat package. We identified marker genes for each cluster by performing differential expression analysis between cells inside and outside that cluster using the FindMarkers function in the Reurat package. After reviewing the clusters, we merged them into nine clusters representing nine cell types (AT1 cells, AT2 cells, bronchiolar epithelial cells, stromal cells_1, stromal cell_2, proliferating cells, stromal cells_3, pulmonary neuroendocrine cells (PNEC) and airway epithelial cells) for further analysis. We re-identified marker genes for the merged nine clusters and selected top positive marker genes per cluster for heatmap plot using the DoHeatmap function in the $\mathrm{R}$ Seurat package. The rest plots were generated using the R ggplot2 package.

\section{RNA-Seq before and following viral infections.}

Organoid infections were performed at an MOI of 0.1 and harvested at 24 hpi in DMEM supplemented with 0.3\% BSA, $4.5 \mathrm{~g} / \mathrm{L}$ D-glucose, $4 \mathrm{mM}$ L-glutamine and $1 \mu \mathrm{g} / \mathrm{ml}$ TPCKtrypsin. Total RNA was extracted in TRIzol (Invitrogen) and DNase I treated using Directzol RNA Miniprep kit (Zymo Research) according to the manufacturer's instructions. RNAseq libraries of polyadenylated RNA were prepared using the TruSeq RNA Library Prep Kit v2 (Illumina) or TruSeq Stranded mRNA Library Prep Kit (Illumina) according to the manufacturer's instructions. cDNA libraries were sequenced using an Illumina NextSeq 500 platform. The resulting single end reads were checked for quality (FastQC v0.11.5) and processed using the processed using the nfcore RNA-seq (v.1.4.2) workflow. Samples had adapters trimmed using Trim Galore (v0.6.4) then ribosomal reads removed using SortMeRNA (v.2.1)before being aligned to human reference 
genome (GRCh38) using STAR aligner ${ }^{30}$ (v.2.6.1). Raw gene counts were quantified using Subread (v.1.6.4) featureCounts.

After further filtering and quality control, $\mathrm{R}$ package edge $\mathrm{R}^{31}$ was used to calculate RPKM and Log2 counts per million (CPM) matrices as well as perform differential expression analysis. Principal component analysis was performed using Log2 CPM values and gene set analysis was run with WebGestalt ${ }^{32}$. Heatmaps and bar plots were generated using Graphpad Prism software, version $7.0 \mathrm{~d}$.

\section{High Throughput Chemical Screening.}

hPSC-derived lung organoids were dissociated using TrypLE for $10 \mathrm{~min}$ in a $37^{\circ} \mathrm{C}$ waterbath and replated into $10 \%$ Matrigel-coated 384-well plates at 10,000 cells/40 $\mu 1$ medium/well. Six hour after plates, compounds from an in-house FDA-approved drug library (Prestwick) were added at $10 \mu \mathrm{M}$. DMSO treatment was used as a negative control. Two hours late, cells will be infected with SARS-CoV-2 pseudo virus (MOI=0.01). After $24 \mathrm{hpi}$, hPSC-COs were harvested for luciferase assay following the Luciferase Assay System protocol (Promega).

\section{QUANTIFICATION AND STATSTICAL ANALYSIS}

$\mathrm{N}=3$ independent biological replicates were used for all experiments unless otherwise indicated. n.s. indicates a non-significant difference. $P$-values were calculated by unpaired two-tailed Student's t-test unless otherwise indicated. ${ }^{*} p<0.05,{ }^{* *} p<0.01$ and $* * * p<0.001$. 


\section{Acknowledgement.}

This work was supported by Department of Surgery, Weill Cornell Medicine (T.E., F.P, S.C.), and (NCI R01CA234614, NIAID 2R01AI107301 and NIDDK R01DK121072 and 1RO3DK117252), Department of Medicine, Weill Cornell Medicine (R.E.S.), by the Defense Advanced Research Projects Agency (DARPA-16-35-INTERCEPT-FP-006, B.T.) and by the Jack Ma Foundation (D.D.H). S.C and R.E.S. are supported as Irma Hirschl Trust Research Award Scholars. V.G. is a Weill Cornell Department of Medicine Fund for the Future awardee, supported by the Kellen Foundation. The authors would like to thank Dr. Harold Varmus at Weill Cornell Medicine for his support and Dr. Tom Moran, Center for Therapeutic Antibody Discovery at the Icahn School of Medicine at Mount Sinai for providing anti-SARS-CoV-SPIKE antibody.

\section{Data Availability}

RNA-seq data is available from the GEO repository database with accession number GSE148697. 


\section{Author Contribution.}

S. C., H. J. C., R.E.S., T. E., D. H., B. T., L.C., and H.W., conceived and designed the experiments. Y.H., L. Y., X. D., F. P., X.P., Z.Z., Y.B., J.L.J, D.N., F.D., and T.M.Y performed organoid differentiation, in vivo transplantation, pseudo-virus infection and drug screening.

P. W, Y. H., performed SARS2-CoV-2 pseudo-entry virus related experiments.

B. N., S.U., and B. T., performed SARS2-CoV-2 related experiments.

F.D., T. Z., J. X. Z., D. X., X. W., D.R., S.H., performed the scRNA-sequencing and bioinformatics analyses.

\section{Declaration of Interests.}

R.E.S. is on the scientific advisory board of Miromatrix Inc. The authors have no conflict of interest. L.C.C. is a founder and member of the board of directors of Agios Pharmaceuticals and is a founder and receives research support from Petra Pharmaceuticals. L.C.C. is an inventor on patents (pending) for Combination Therapy for PI3K-associated Disease or Disorder, and The Identification of Therapeutic Interventions to Improve Response to PI3K Inhibitors for Cancer Treatment. L.C.C. is a co-founder and shareholder in Faeth Therapeutics. T.M.Y. is a stockholder and on the board of directors of DESTROKE, Inc., an early-stage start-up developing mobile technology for automated clinical stroke detection. 
Table S3. Antibodies used for immunocytochemistry, intracellular flow cytometry analysis and western blotting analysis.

\begin{tabular}{|c|c|c|c|c|c|c|}
\hline Usage & Antibody & Clone \# & Host & $\begin{array}{l}\text { Catalog } \\
\#\end{array}$ & Vendor & Dilution \\
\hline $\begin{array}{l}\text { Immunocytoche } \\
\text { mistry }\end{array}$ & $\begin{array}{l}\text { Human ACE-2 } \\
\text { Antibody }\end{array}$ & Polyclonal & Goat & \#AF933 & $\begin{array}{l}\text { R\&D } \\
\text { Systems }\end{array}$ & $1: 200$ \\
\hline $\begin{array}{l}\text { Immunocytoche } \\
\text { mistry }\end{array}$ & $\begin{array}{l}\text { Firefly } \\
\text { luciferase } \\
\text { Monoclonal } \\
\text { Antibody (CS } \\
17)\end{array}$ & CS 17 & Mouse & $\begin{array}{l}\# 35- \\
6700\end{array}$ & $\begin{array}{l}\text { Thermo } \\
\text { Fisher } \\
\text { Scientific }\end{array}$ & $1: 200$ \\
\hline $\begin{array}{l}\text { Immunocytoche } \\
\text { mistry }\end{array}$ & $\begin{array}{l}\text { Anti-NKX2.1 } \\
\text { Antibody }\end{array}$ & Polyclonal & Rabbit & $\begin{array}{l}\text { \#WRA } \\
\text { B-1231 }\end{array}$ & $\begin{array}{l}\text { Seven } \\
\text { Hills } \\
\text { Bioreagent } \\
\text { S }\end{array}$ & $1: 500$ \\
\hline $\begin{array}{l}\text { Immunocytoche } \\
\text { mistry }\end{array}$ & $\begin{array}{l}\text { Anti-SOX2 } \\
\text { Antibody }\end{array}$ & $\mathrm{Y}-17$ & Goat & $\begin{array}{l}\text { \#sc- } \\
17320 \\
\end{array}$ & Santa Cruz & $1: 150$ \\
\hline $\begin{array}{l}\text { Immunocytoche } \\
\text { mistry }\end{array}$ & $\begin{array}{l}\text { Anti-FOXA2 } \\
\text { Antibody }\end{array}$ & M-20 & Goat & $\begin{array}{l}\text { \#sc- } \\
6554\end{array}$ & Santa Cruz & $1: 150$ \\
\hline $\begin{array}{l}\text { Immunocytoche } \\
\text { mistry }\end{array}$ & $\begin{array}{l}\text { Anti-SP-C } \\
\text { Antibody }\end{array}$ & Polyclonal & Rabbit & $\begin{array}{l}\text { \#WRA } \\
\text { B- } \\
76694\end{array}$ & $\begin{array}{l}\text { Seven } \\
\text { Hills } \\
\text { Bioreagent } \\
\text { s }\end{array}$ & $1: 500$ \\
\hline $\begin{array}{l}\text { Immunocytoche } \\
\text { mistry }\end{array}$ & $\begin{array}{l}\text { Anti-SP-B } \\
\text { Antibody }\end{array}$ & Polyclonal & Rabbit & $\begin{array}{l}\text { Cat\# } \\
\text { WRAB- } \\
48604\end{array}$ & $\begin{array}{l}\text { Seven } \\
\text { Hills } \\
\text { Bioreagent } \\
\text { S } \\
\end{array}$ & $1: 500$ \\
\hline $\begin{array}{l}\text { Immunocytoche } \\
\text { mistry }\end{array}$ & $\begin{array}{l}\text { Anti-SARS- } \\
\text { CoV-Spike } \\
\text { antibody } \\
\text { [2B3E5] }\end{array}$ & & Mouse & & $\begin{array}{l}\text { Provided } \\
\text { by Dr. } \\
\text { Tom } \\
\text { Moran }\end{array}$ & $1: 100$ \\
\hline $\begin{array}{l}\text { Immunocytoche } \\
\text { mistry }\end{array}$ & $\begin{array}{l}\text { Donkey anti- } \\
\text { Mouse IgG } \\
(\mathrm{H}+\mathrm{L}) \quad \text { Highly } \\
\text { Cross-Adsorbed } \\
\text { Secondary } \\
\text { Antibody, } \\
\text { Alexa Fluor } 488\end{array}$ & Polyclonal & Donkey & $\begin{array}{l}\text { \#A- } \\
21202\end{array}$ & $\begin{array}{l}\text { Thermo } \\
\text { Fisher } \\
\text { Scientific }\end{array}$ & $1: 500$ \\
\hline $\begin{array}{l}\text { Immunocytoche } \\
\text { mistry }\end{array}$ & $\begin{array}{l}\text { Donkey anti- } \\
\text { Rabbit } \\
(\mathrm{H}+\mathrm{L})\end{array}$ & Polyclonal & Donkey & $\begin{array}{l}\# A- \\
21207\end{array}$ & $\begin{array}{l}\text { Thermo } \\
\text { Fisher } \\
\text { Scientific }\end{array}$ & $1: 500$ \\
\hline
\end{tabular}




\begin{tabular}{|c|c|c|c|c|c|c|}
\hline & $\begin{array}{l}\text { Secondary } \\
\text { Antibody, } \\
\text { Alexa Fluor } 594 \\
\text { conjugate }\end{array}$ & & & & & \\
\hline $\begin{array}{l}\text { Immunocytoche } \\
\text { mistry }\end{array}$ & $\begin{array}{l}\text { Donkey anti- } \\
\text { Goat IgG }(\mathrm{H}+\mathrm{L}) \\
\text { Cross-Adsorbed } \\
\text { Secondary } \\
\text { Antibody, } \\
\text { Alexa Fluor } 647\end{array}$ & Polyclonal & Donkey & $\begin{array}{l}\text { \#A- } \\
21447\end{array}$ & $\begin{array}{l}\text { Thermo } \\
\text { Fisher } \\
\text { Scientific }\end{array}$ & $1: 500$ \\
\hline
\end{tabular}

Table S3. Primers used for qRT-PCR.

\begin{tabular}{|l|l|}
\hline Primer name & Sequence \\
\hline ACTB-Forward & CGTCACCAACTGGGACGACA \\
\hline ACTB-Reverse & CTTCTCGCGGTTGGCCTTGG \\
\hline SARS-CoV-2-TRS-L & CTCTTGTAGATCTGTTCTCTAAACGAAC \\
\hline SARS-CoV-2-TRS-N & GGTCCACCAAACGTAATGCG \\
\hline
\end{tabular}




\section{REFERENCES}

1 Montoro, D. T. et al. A revised airway epithelial hierarchy includes CFTR-expressing ionocytes. Nature 560, 319-324, doi:10.1038/s41586-018-0393-7 (2018).

2 Chen, Y. W. et al. A three-dimensional model of human lung development and disease from pluripotent stem cells. Nat Cell Biol 19, 542-549, doi:10.1038/ncb3510 (2017).

3 Huang, S. X. et al. The in vitro generation of lung and airway progenitor cells from human pluripotent stem cells. Nat Protoc 10, 413-425, doi:10.1038/nprot.2015.023 (2015).

4 Huang, S. X. et al. Efficient generation of lung and airway epithelial cells from human pluripotent stem cells. Nat Biotechnol 32, 84-91, doi:10.1038/nbt.2754 (2014).

5 Mou, H. et al. Generation of multipotent lung and airway progenitors from mouse ESCs and patient-specific cystic fibrosis iPSCs. Cell Stem Cell 10, 385-397, doi:10.1016/j.stem.2012.01.018 (2012).

6 https://doi.org/10.1101/742320.

7 Jacob, A. et al. Differentiation of Human Pluripotent Stem Cells into Functional Lung Alveolar Epithelial Cells. Cell Stem Cell 21, 472-488 e410, doi:10.1016/j.stem.2017.08.014 (2017).

8 Hawkins, F. et al. Prospective isolation of NKX2-1-expressing human lung progenitors derived from pluripotent stem cells. J Clin Invest 127, 2277-2294, doi:10.1172/JCI89950 (2017).

9 McCauley, K. B. et al. Efficient Derivation of Functional Human Airway Epithelium from Pluripotent Stem Cells via Temporal Regulation of Wnt Signaling. Cell Stem Cell 20, 844857 e846, doi:10.1016/j.stem.2017.03.001 (2017).

10 Hurley, K. et al. Reconstructed Single-Cell Fate Trajectories Define Lineage Plasticity Windows during Differentiation of Human PSC-Derived Distal Lung Progenitors. Cell Stem Cell 26, 593-608 e598, doi:10.1016/j.stem.2019.12.009 (2020).

11 Jacob, A. et al. Derivation of self-renewing lung alveolar epithelial type II cells from human pluripotent stem cells. Nat Protoc 14, 3303-3332, doi:10.1038/s41596-019-0220-0 (2019).

12 Miller, A. J. et al. Generation of lung organoids from human pluripotent stem cells in vitro. Nat Protoc 14, 518-540, doi:10.1038/s41596-018-0104-8 (2019).

13 Dye, B. R. et al. In vitro generation of human pluripotent stem cell derived lung organoids. Elife 4, doi:10.7554/eLife.05098 (2015).

14 Miller, A. J. et al. In Vitro Induction and In Vivo Engraftment of Lung Bud Tip Progenitor Cells Derived from Human Pluripotent Stem Cells. Stem Cell Reports 10, 101-119, doi:10.1016/j.stemcr.2017.11.012 (2018).

15 Chen, H. J. et al. Generation of pulmonary neuroendocrine cells and SCLC-like tumors from human embryonic stem cells. J Exp Med 216, 674-687, doi:10.1084/jem.20181155 (2019).

16 Hoffmann, M. et al. SARS-CoV-2 Cell Entry Depends on ACE2 and TMPRSS2 and Is Blocked by a Clinically Proven Protease Inhibitor. Cell, doi:10.1016/j.cell.2020.02.052 (2020).

17 Lukassen, S. et al. SARS-CoV-2 receptor ACE2 and TMPRSS2 are primarily expressed in bronchial transient secretory cells. EMBO J, e105114, doi:10.15252/embj.20105114 (2020). 
18 Whitt, M. A. Generation of VSV pseudotypes using recombinant DeltaG-VSV for studies on virus entry, identification of entry inhibitors, and immune responses to vaccines. $J$ Virol Methods 169, 365-374, doi:10.1016/j.jviromet.2010.08.006 (2010).

19 Nie, J. et al. Establishment and validation of a pseudovirus neutralization assay for SARSCoV-2. Emerg Microbes Infect 9, 680-686, doi:10.1080/22221751.2020.1743767 (2020).

20 https://doi.org/10.1101/2020.05.02.073320.

21 Heaton, N. S. \& Randall, G. Multifaceted roles for lipids in viral infection. Trends Microbiol 19, 368-375, doi:10.1016/j.tim.2011.03.007 (2011).

22 https://doi.org/10.1101/2020.01.26.919985.

23 10.1016/j.cell.2020.04.026, h. D.

24 Coleman, C. M. et al. Abelson Kinase Inhibitors Are Potent Inhibitors of Severe Acute Respiratory Syndrome Coronavirus and Middle East Respiratory Syndrome Coronavirus Fusion. J Virol 90, 8924-8933, doi:10.1128/JVI.01429-16 (2016).

25 Sisk, J. M., Frieman, M. B. \& Machamer, C. E. Coronavirus S protein-induced fusion is blocked prior to hemifusion by Abl kinase inhibitors. J Gen Virol 99, 619-630, doi:10.1099/jgv.0.001047 (2018).

26 Zhao, X. et al. Immunization-Elicited Broadly Protective Antibody Reveals Ebolavirus Fusion Loop as a Site of Vulnerability. Cell 169, 891-904 e815, doi:10.1016/j.cell.2017.04.038 (2017).

27 Chen, H. J. et al. Chemokine 25-induced signaling suppresses colon cancer invasion and metastasis. J Clin Invest 122, 3184-3196, doi:10.1172/JCI62110 (2012).

28 Stuart, T. et al. Comprehensive Integration of Single-Cell Data. Cell 177, 1888-1902 e1821, doi:10.1016/j.cell.2019.05.031 (2019).

29 van den Brink, S. C. et al. Single-cell sequencing reveals dissociation-induced gene expression in tissue subpopulations. Nat Methods 14, 935-936, doi:10.1038/nmeth.4437 (2017).

30 Dobin, A. et al. STAR: ultrafast universal RNA-seq aligner. Bioinformatics 29, 15-21, doi:10.1093/bioinformatics/bts635 (2013).

31 Robinson, M. D., McCarthy, D. J. \& Smyth, G. K. edgeR: a Bioconductor package for differential expression analysis of digital gene expression data. Bioinformatics 26, 139-140, doi:10.1093/bioinformatics/btp616 (2010).

32 Liao, Y., Wang, J., Jaehnig, E. J., Shi, Z. \& Zhang, B. WebGestalt 2019: gene set analysis toolkit with revamped UIs and APIs. Nucleic Acids Res 47, W199-W205, doi:10.1093/nar/gkz401 (2019). 